September 2021

Paper accepted for publication in the American Society of Civil Engineers ASCE Journal of Structural Engineering, as part of Special Collection: Twenty years of advances in Disproportionate collapse research and best practices since 9/11/2001. Paper may be cited before publication as: Ulaeto, N.W., J. Sagaseta, and M. Chryssanthopoulos. Forthcoming. "Horizontal collapse propagation of concrete flat slabs supported on columns." ASCE Journal of Structural Engineering. https://doi.org/ 10.1061/(ASCE)ST.1943-541X.0003245.

Paper title:

\title{
Horizontal collapse propagation of concrete flat slabs supported on columns
}

by N. W. Ulaeto ${ }^{1}$, J. Sagaseta ${ }^{2 *}$, M. Chryssanthopoulos ${ }^{2}$

1- University of Uyo, Uyo, Nigeria; former PhD student at ${ }^{2}$

2- University of Surrey, Guildford, United Kingdom

*Corresponding author:

Dr. Juan Sagaseta

University of Surrey

Faculty of Engineering \& Physical Sciences

Department of Civil and Environmental Engineering

Guildford, Surrey GU2 7XH

UK

Email: j.sagaseta@surrey.ac.uk 
1 Horizontal collapse propagation of concrete flat slabs supported on columns

\section{N. W. Ulaeto ${ }^{1}$, J. Sagaseta ${ }^{2}$, and M. Chryssanthopoulos ${ }^{3}$}

${ }^{1}$ Lecturer at University of Uyo, Uyo, Nigeria.

${ }^{2}$ Reader at University of Surrey, Guildford, UK. Email: j.sagaseta@surrey.ac.uk (corresponding author)

${ }^{3}$ Professor at University of Surrey, Guildford, UK.

\section{Abstract}

The progressive collapse of the World Trade Centre showed the devastating consequences of pancake-type collapses, triggering significant research on failed floor impacts for different forms of construction. In current high-rise construction, concrete flat slabs supported on columns are widely used and, in this case, the fall of the slab could be prevented depending on the detailing and the horizontal propagation of the collapse from one support to adjacent supports. The activation and interaction of different phenomena during horizontal propagation governed by the slab-column response is investigated in this study for cases of flat slabs with and without integrity reinforcement. The paper focuses on slabs without punching reinforcement which are more critical. A slab system analytical model is presented based on a column removal scenario considering the dynamic response of the column-slab connections before and after punching including membrane effects. The model was verified using finite element models with solid elements at the connections. The results highlighted the key role of integrity reinforcement towards preventing slabs from falling by means of activating tensile membrane action concentrated around the columns. 
Introduction

29 Twenty years ago the tragic events leading to the progressive collapse of the World Trade

30 Centre in New York showed the dramatic consequences of pancake-type collapses, reigniting

31 the discussion internationally about design for structural robustness. Different well-known

32 building collapses from World War II, Ronan Point, Alfred P. Murrah Federal Building,

33 Sampoong Department Store described in the literature (e.g. Ellingwood and Dusenberry 2005,

34 Byfield et al. 2014, Adam et al. 2018, Russell et al. 2019) and more recent underground car park failures in Europe (Fernández Ruiz et al. 2013) show that the response to accidental events can vary significantly depending on the form of construction. One of the main reasons behind the broad range of responses is the different response of the connections in the structure which has a critical role on the propagation of failure.

Current forms of construction include traditional frame structures, modular construction and flat slab construction amongst others. In current high-rise building schemes for residential and commercial purposes, flat slab construction (slabs supported on columns) are highly popular due to their reduced story height, elimination of clashes with suspended services and flexibility for partition layouts. In this form of construction the response of slab-column connections in accidental events is governed by flexure until punching occurs at low deformations followed by a sudden reduction in the shear transfer at the connection and stiffness (post-punching response) which can be mitigated using integrity reinforcement. Fig. (1) shows this type of

47 failure in a car park structure in the UK due to poor detailing and unchecked deterioration and 48 in an underground car park in Spain due to overloading after drainage modifications in the 49 earth cover. 

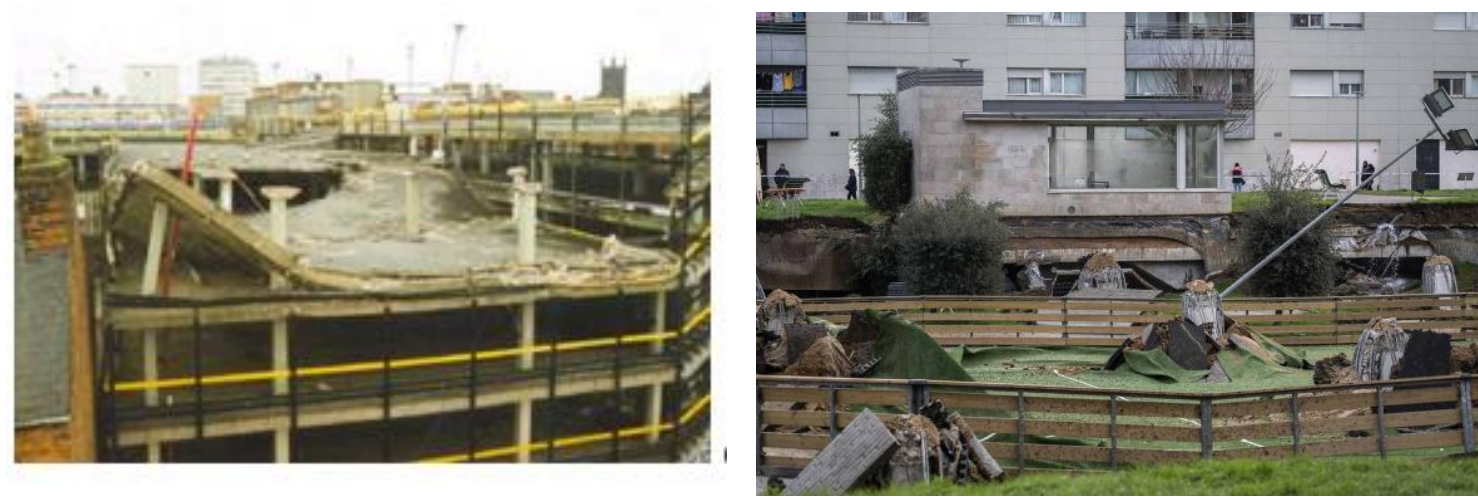

Fig. 1. Collapse of flat slab structures: (a) Pipers Row Car Park, Wolverhampton (Wood, 2001); (b) Nueva Montaña car park, Santander (photo by Joaquín Gomez Sastre).

Designing for the unforeseen is challenging and building codes reflect this through different proposed strategies for robustness design (Ellingwood and Dusenberry 2005, Starossek et al. 2011, IStructE 2010). These strategies follow design philosophies introducing different lines of defense or layers of protection (LOP). A first LOP is to prevent the failure initiation. This can be achieved as described in Starossek et al. (2011) externally from the structure through protection or event control and internally to the structure through increased local resistance of key elements (e.g. slab-column connections in flat slabs) although the latter can be uneconomic or difficult to achieve for unknown actions. A second LOP is to prevent disproportionate propagation of the failure through the analysis of alternative load paths (ALP) which is the main focus of this paper; segmentation can be also adopted alternatively as suggested by Ellingwood and Dusenberry (2005) and Starossek et al. (2011) amongst others.

In flat slabs, the local failure of one column (failure initiation) can propagate horizontally to immediately opposite columns shown in Fig. (2) as reported by Hawkins and Mitchel (1979), Regan (1981), Fernández Ruiz et al. (2013), Sagaseta et al. (2017) and Garzón-Roca et al. (2021). Further horizontal propagation of failure to other slab-column connections can result into the slab falling onto the floor below. This horizontal propagation and interaction between post-punching in one connection and punching in the adjacent connection is not well known; tests on slab system assemblies subject to column removal (Yi et al. 2014, Russell et al. 2015, 
71 Peng 2015, Xue et al. 2018) provided useful information on dynamic effects in the slab

although the information on the slab-column connections is limited due to the boundary conditions adopted. Research on slab impacting on the floor below showed that this often triggered the vertical progression of the collapse due to the high dynamic shear demands introduced in the connections (Vlassis et al. 2009, Olmati et al. 2017, Yankelevsky et al. 2020) and therefore this scenario should be prevented, especially when the size of the debris falling is significant.

This paper focuses on the horizontal propagation of failure at a slab system level to provide a better understanding of the interaction between the phenomena preventing or leading to slab falling. Considerations are made in the proposed model on flexure, compressive membrane action, punching and post-punching leading to tensile membrane action. An analytical slab progressive collapse model is proposed which was verified against advanced numerical models. Dynamic considerations are made in the analytical model using the pseudo-static response of the slab system based on energy balance as proposed in the Ductility-Centre approach by Izzuddin et al. (2018) and punching is assessed through the Critical Shear Crack Theory (CSCT) rotation-based approach by Muttoni (2008). The work contributes to previous research on progressive collapse analysis at slab system level (Keyvani et al. 2014, Liu et al. 2015) where post-punching modelling was simplified significantly. In this work the asymmetric post-punching model for progressive collapse analyses was adopted which was derived and validated in Ulaeto and Sagaseta (2021). This model is based on the early work on post-punching on isolated connections from Melo and Regan (1998), Fernández-Ruiz et al. (2013) and constitutive models from Mirzaei (2010) and Habibi et al. (2014). The results in this paper provide relevant information on the role of integrity reinforcement for the critical case of flat slabs without punching reinforcement and the activation of tensile membrane action after punching. 
97 An analytical model is proposed for the slab system to provide information on the dynamic horizontal propagation of collapse after sudden internal column removal. This section presents the main equations and fundamentals of this approach. The model calculates the nonlinear static response of the system considering: (i) gravity load redistribution, (ii) flexural and compressive membrane action, (iii) punching around the connections and (iv) asymmetric postpunching shear at the connections resulting into tensile membrane action. Once the nonlinear static response is obtained, the pseudo-static response is calculated from energy considerations as proposed by Izzuddin et al. (2008) in order to assess the dynamic peak response. The model was used to assess how post-punching and detailing influences the horizontal propagation of failure.

107 The analytical model is based on a static push-down analysis of an interior column in which different deformation modes are identified sequentially as the deflection at the point of the removed column is increased and punching occurs at the opposite and adjacent columns as

110 shown in Fig. (2) for one quarter of the slab segment. Three deformation modes are considered

111 which absorb (by means of strain energy) most of the potential energy introduced by the gravity

112 loads after sudden column removal. The formulation is written in terms of a single degree of

113 freedom, i.e. total vertical displacement at the point of column removal $\left(w_{c t r}\right)$, to calculate the 114 reactions at the supports. Vertical deflections near the opposite and adjacent columns are

115 derived at different control points from compatibility assumptions as described in more detail 116 in subsequent sections.

117 The first deformation mode considers the slab system response after internal column removal 118 prior to punching failure of the opposite column. Flexure is the primary response mode around 119 the adjoining connections as the slab deforms to establish a new state of equilibrium. As 120 cracking develops in the bottom of the slab at the point of column removal, the slab dilates and 
121 compressive membrane action (CMA) is activated if the slab is confined laterally (in-plane

122 confinement); this can be the case for interior columns. At the second deformation mode the

123 opposite connection has failed in punching with the activation of post-punching shear. The

124 total vertical displacement of the slab at the opposite connection is $w_{c t r . o p p .2}$ while at the point

125 of column removal is $w_{c t r .2}$ at this stage of the response. The third deformation mode is when

126 both the opposite and adjacent connections have failed in punching shear. In this deformation

127 mode the opposite connection is at an advanced stage of post-punching whereas the adjacent

128 connection is at the early stages of post-punching and gravity load is redistributed to other

129 adjoining columns. The overall modelling and analysis stages are summarised in Fig. (2b)

130 which makes references to equations described in the following sections.

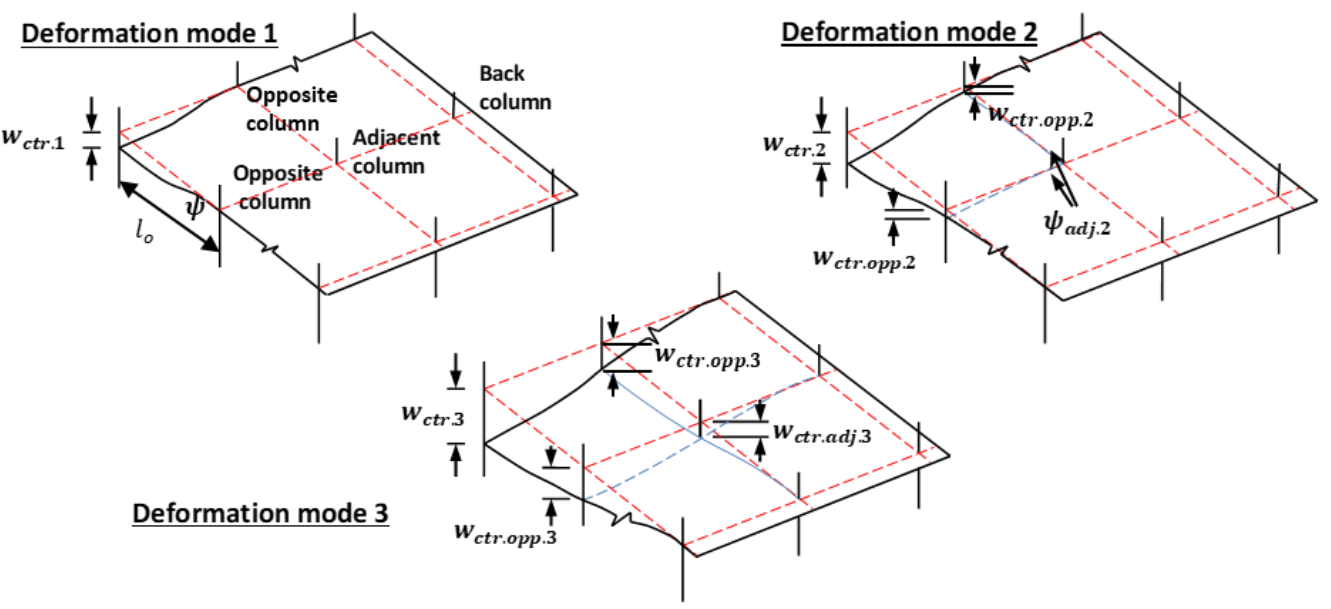

$131 \quad$ (a)

132

133

134

135

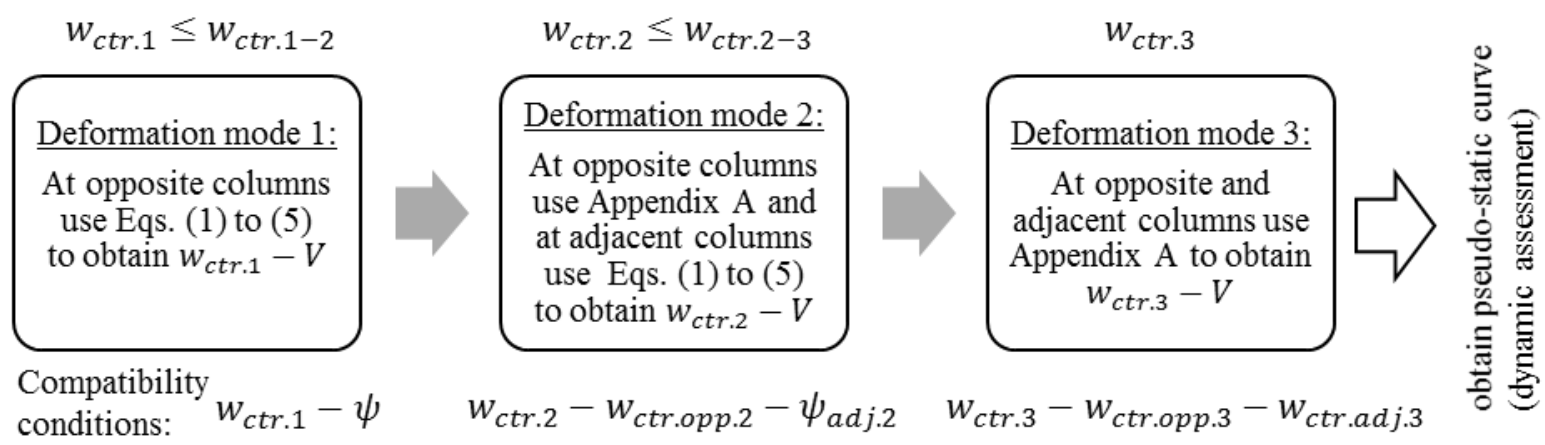

(b)

Fig. 2. Horizontal failure propagation model after internal column removal (quarter flat slab system model): (a) deformations modes and (b) analysis flow-chart. 
137 Different flexural models can be used for deformation mode 1 until punching occurs around

138 the opposite connections, as shown by Muttoni (2008) with different levels of approximation 139 as proposed in Model Code 2010 (fib 2013). Refined considerations can be made to take into 140 account CMA for fully restrained slabs as shown by Einpaul et al. (2016), introducing a factor $141 f_{\mathrm{CMA}}$ which is further discussed in this section for column removal situations. Punching at the 142 opposite connection and the flexural response was assessed in this work using Level of 143 Approximation II from Model Code 2010 given by Eq. (1) which is valid until punching; in 144 Model Code 2010 CMA is neglected $\left(f_{\text {CMA }}=1\right)$.

$$
\psi=1.5 \frac{r_{s}}{d} \frac{f_{y}}{E_{s}}\left(\frac{V}{k m_{R}}\right)^{\frac{3}{2}} f_{\mathrm{CMA}}
$$

146 where $\psi$ is the slab rotation near the opposite column along the direction of the removed

147 column; $r_{s}$ is the distance from the axis of the opposite column to the point of counter-flexure 148 measured towards the removed column (for internal column removal $r_{s}=0.44 L_{0}$ where $L_{0}$ is 149 the span length between column centrelines before column removal); $d$ is the effective depth 150 of the slab measured to the centroid of the reinforcement layers in tension; $f_{y}$ and $E_{s}$ are the steel yield strength and Young's modulus, respectively; $m_{R}$ is the average flexural strength per unit width in the column strip and $k$ is the ratio between the shear and the average moment

153 per unit width which is approximately equal to 8 for small eccentricities in the column reaction 154 such as those in internal column removal situations (Sagaseta et al. 2017).

155 Deflection mode 1 ends at $w_{c t r .1}=w_{c t r .1-2}$ when punching in the opposite column occurs. 156 Eq. (2) is the punching failure criterion from the CSCT (Muttoni 2008) which was used in the case study shown in subsequent section for a slab without punching reinforcement. The 158 punching strength $V_{R}$ and slab rotation at punching $\psi_{R}$ are obtained solving for $V=V_{R}$ and

$159 \psi=\psi_{R}$ in Eq. (1) and Eq. (2). In Eq. (2), $f_{c}$ is the concrete compression strength, $d_{g}$ is the 
maximum aggregate size (in $\mathrm{mm}$ ) and $b_{0}$ is the length of the shear-resisting control perimeter as defined in Model Code 2010 (fib 2013).

$$
\frac{V_{R}}{b_{0} d \sqrt{f_{c}}}=\frac{3 / 4}{1+15 \frac{\psi \cdot d}{16+d g}}
$$

In order to apply dynamic considerations in the slab system, the proposed model is formulated

based on a single degree of freedom $w_{c t r}$ and therefore a compatibility condition is needed between $\psi$ and $w_{c t r}$. This compatibility relationship allows to calculate bending moments, shear and ultimately slab reactions for different values of $w_{c t r}$. For general purposes of column removal in slab-column subsystems, Sagaseta et al. (2017) proposed a compatibility relationship between slab displacement at the point of column removal $\left(w_{c t r}\right)$ (sagging) and the slab rotation close to the column $(\psi)$ as $w_{c t r} \approx(2 / 3) L_{0} \psi$ based on an elastic deformation profile. This relationship is influenced by the amount of hogging reinforcement at the opposite column $\left(\rho_{\text {hog }}\right)$ and the amount of sagging reinforcement where the column is removed $\left(\rho_{\text {sag }}\right)$, which is normally low. However, using the elastic estimate can result in the underestimation of $w_{c t r}$ for high values of $\rho_{\text {hog }}$ and $\rho_{\text {hog }} / \rho_{\text {sag }}$.

In order to address this, a more refined expression was proposed by Ulaeto (2018) given by Eq. (3). This expression was derived based on the observation that in flat slabs the slab rotation increases significantly close to the column and it remains constant at distances of about $2 d$ to $4 d$ from the column face (Guandalini 2005, Tassinari 2011) before decreasing to zero at the point of maximum sagging moments. A control deflection point is adopted in this work at a distance of $3.5 \mathrm{~d}$ from the column face; this distance is around $0.28 L_{0}$ for a standard slab with span-to-depth ratio of around 25 and column length-to-depth ratio of around 1.3.

$$
w_{c t r}=\varsigma\left(0.28 L_{0}\right) \psi
$$

In Eq. (3), $\varsigma$ is the ratio of the displacement at the removed column to that at a control point at

$1830.28 L_{0}$ from the centre of the column where rotation remains constant. The relationship between $\varsigma$ and $\rho_{\text {hog }} / \rho_{\text {sag }}$ obtained by Ulaeto (2018) is given in Eq. (4) where $f$ is a reduction 
185 factor which varied with the level of loading $\left(f=V / V_{\text {flex }}\right)$, although the variation for loads

186 above the cracking load was negligible and a constant value $(f=1)$ was adopted.

187

$$
\varsigma=0.32 f\left[2.0\left(\frac{\rho_{\text {hog }}}{\rho_{\text {sag }}}\right)+6.5\right] \ldots(4)
$$

188 Fig. (3) shows that Eq. (3) gave consistent results with a parametric analysis using nonlinear

189 FE analyses with shell elements conducted by Tassinari (2011) as well as laboratory results

190 from Yi et al. (2014) of an internal column removal static test. In these analyses, $\rho_{\text {hog }}$ varied

191 from $1.5 \%$ to $0.75 \%$ and $\rho_{\text {hog }} / \rho_{\text {sag }}$ varied from 5 to 1.5 covering a wide range of values

192 typically found in practice.

193
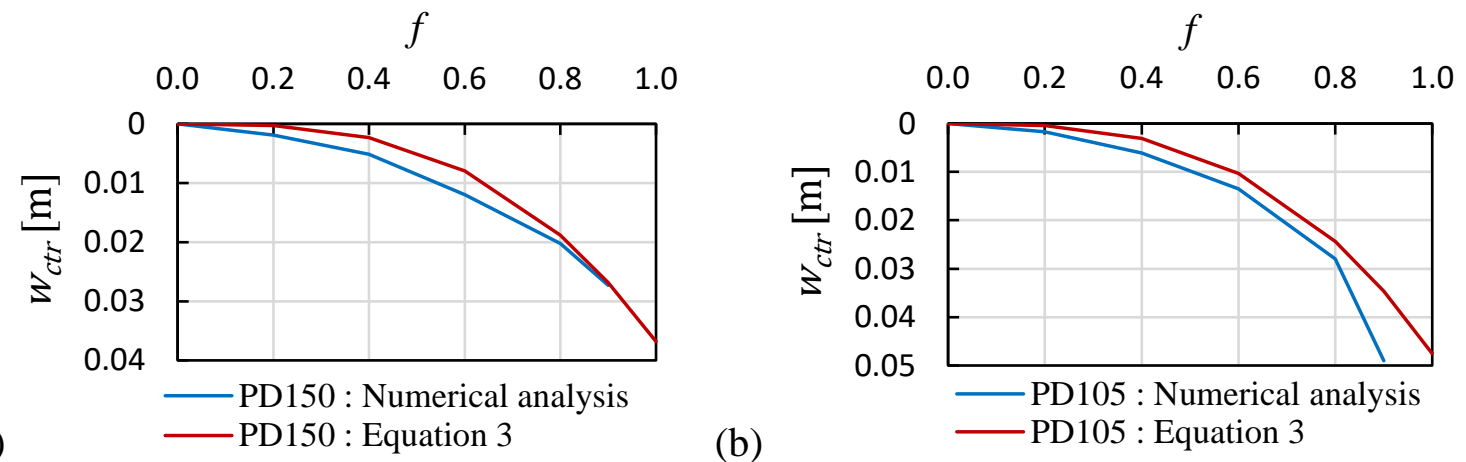

(b)
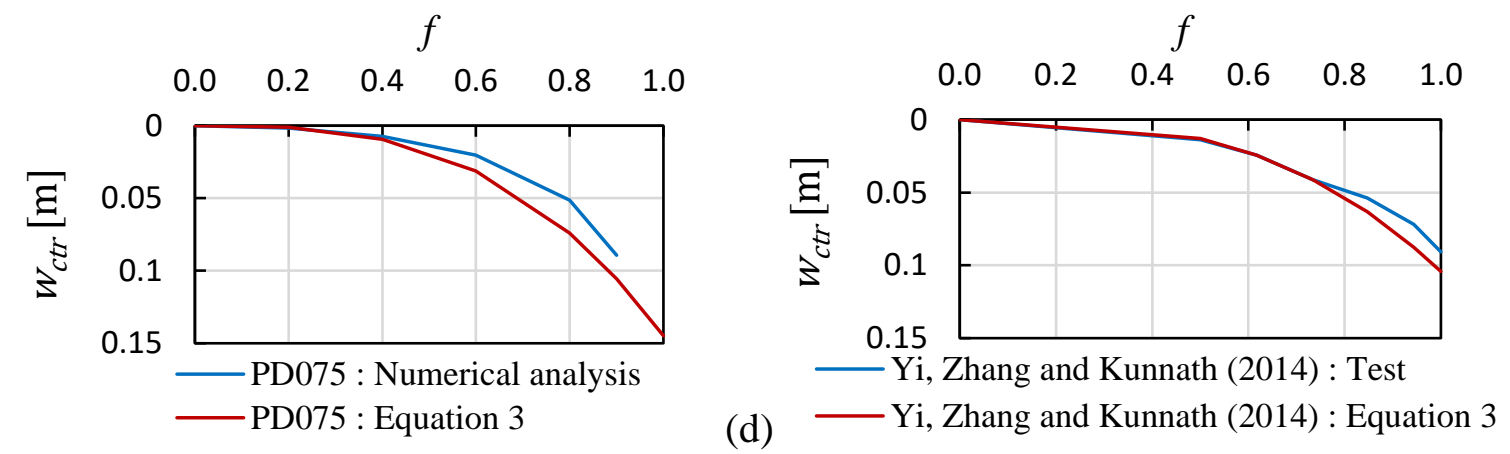

195

Fig. 3. Comparison between numerical prediction of displacement at removed column

196 location and Eq. (3): (a) to (c) cases in Tassinari (2011) with $\boldsymbol{\rho}_{\boldsymbol{h o g}}=1.5 \%, 1.05 \%$ and $0.75 \%$

197 in PD150, PD105 and PD075 respectively; (d) comparison with test from Yi et al. (2014). 
198 Regarding the CMA component, if the slab is confined laterally as shown in Fig. (4), the 199 response in the deformation mode 1 can be significantly stiffer. This can be considered by using 200 factor, $f_{C M A}$ in Eq. (5) proposed by Einpaul et al. (2016)

$$
f_{C M A}=k_{\psi}\left(1-\frac{m_{c r}}{\eta_{R} m_{R . h o g}}\right)
$$

202 where parameter $k_{\psi}$ is the factor of proportionality for rotation at the onset of yielding in a continuous slab relative to the corresponding rotation in an isolated specimen, $\eta_{R}$ is the ratio between sagging and hogging moment capacities, $m_{c r}$ is the cracking moment per unit width of slab, $m_{R . h o g}$ is the maximum hogging moment per unit width of slab. Eq. (5) was originally conceived for design of continuous flat slabs, looking at internal columns with equal orthogonal spans and without consideration of column removal; hence $k_{\psi}$ and $\eta_{R}$ were taken as 1 and 0.5 respectively for common cases in practice. For the column removal situations investigated in this work, $k_{\psi}$ was 2.5 and $\eta_{R}$ was lower than 0.5 since the sagging reinforcement at the slab

210 where the column was removed was minimal. For the case study shown in subsequent sections $211 \eta_{R}$ was 0.28 although in most practical cases $\eta_{R}$ is around 0.15 (ACI 352.1R-89 1997, The

212 Concrete Society 2007). Eq. (1) was verified for the case study described in the subsequent 213 section against shear-rotation curves obtained from FE models using shell elements with lateral 214 restraint; Fig. (4) shows that the curves considering CMA were comparable. 
(a)

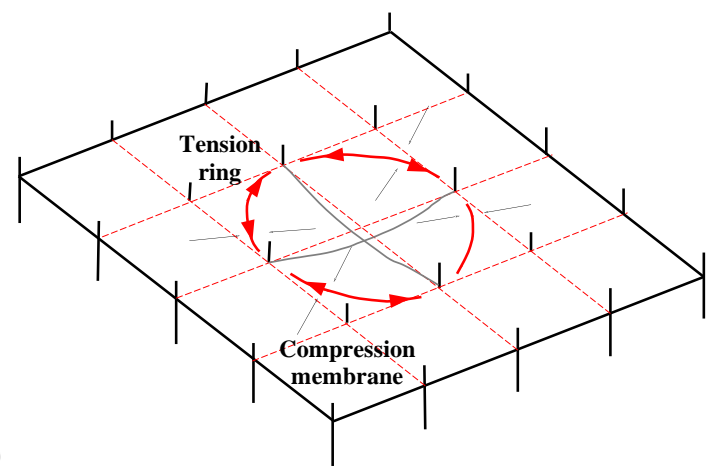

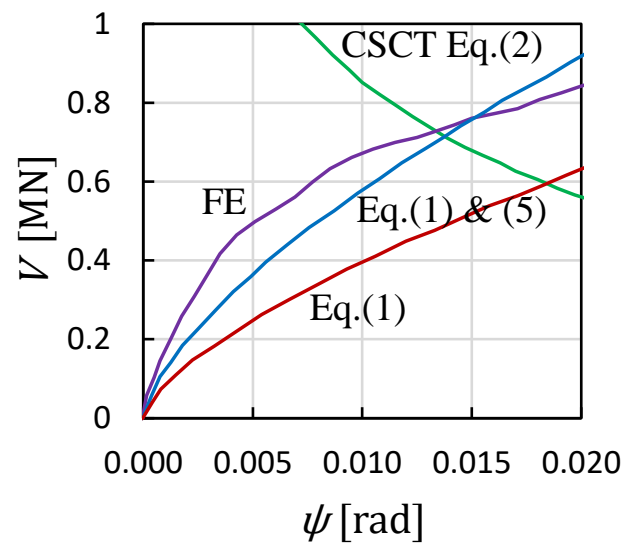

(b)

Fig. 4. (a) Compressive membrane action after column removal and (b) shear-rotation relationship using Eq. (1) and (5) compared to FE predictions using shell elements (case study shown in Fig. 7).

\section{Deformation modes 2 and 3 after punching}

Deformation mode 2 of the slab system response occurs when the opposite columns have punched and the slab at the adjacent columns behaves predominantly in flexure. As shown in Fig. (2), the main kinematic parameters considered in this deformation mode were the vertical displacement at the point of column removal $\left(w_{c t r .2}\right)$, the vertical displacement at the opposite column $\left(w_{\text {ctr.opp.2 }}\right)$ and the slab rotation around the adjacent column at the side towards the opposite column $\left(\psi_{a d j .2}\right)$. These parameters are related to each other through different compatibility relationships. The slab rotation $\psi_{a d j .2}$ is calculated in terms of $w_{c t r . o p p .2}$ using

Eq. (3). The vertical displacement at the opposite column $w_{c t r . o p p .2}$ is related to the column removal displacement $w_{c t r .2}$ according to $w_{c t r . o p p .2} \approx 0.43 w_{c t r .2}$. This relationship was obtained based on the deflected shape of a continuous plate (with equal spans) in deformation mode 2 in Fig. (2) which results in an almost linear deflection profile along a line drawn from the removed column at $w_{c t r .2}$ to zero deflection at around a distance of $0.25 L_{0}$ from the back columns. A similar relationship was adopted for deformation mode 3 , i.e. $w_{c t r . a d j .3} \approx$ 
$2330.43 w_{\text {ctr.opp.3 }}$. A different value could be derived in a slab with different spans using the linear

234 deflection assumption.

235 The reaction at the adjacent column was obtained from flexural considerations using Eq. (1)

236 with the limit at $w_{c t r .2}=w_{c t r .2-3}$, given by punching in Eq. (2) from the CSCT formulation

237 similar to the opposite column reaction in deformation mode 1 . The reaction developed at the

238 opposite column in deformation mode 2 was estimated using the post-punching response model

239 in Ulaeto and Sagaseta (2021) which is summarised in Appendix A. As shown in Ulaeto and

240 Sagaseta (2021) this model is also applicable to asymmetric cases shown in Fig. (5) by carrying

241 out the calculation for each sector separately corresponding to each column face. The four

242 sectors corresponded to (i) the critical side between the opposite and removed column, (ii) the

243 opposite side between the opposite and back column and (iii) the two adjacent sides between

244 the opposite and adjacent columns. The control points for the vertical deflections at each sector

245 were positioned at $3.5 \mathrm{~d}$ from the column face for consistency with the flexural control points

246 in deformation mode 1 and deflection ratios between them were adopted.

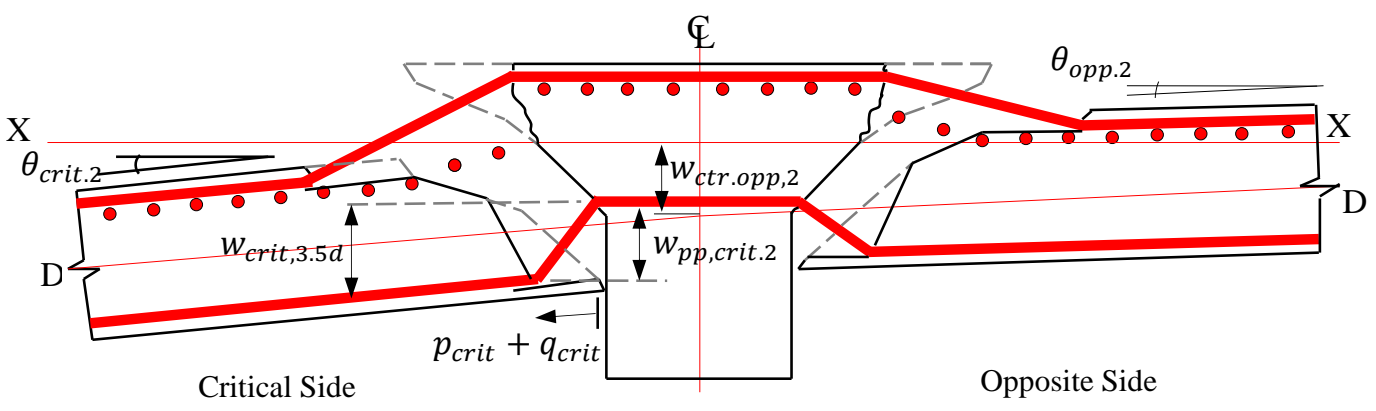

Fig. 5. Post-punching of continuous flat slab at opposite column.

Ulaeto and Sagaseta (2021) showed that in asymmetric post-punching, damage (including

250 fracture of the reinforcement) localises at the critical side. This response is captured by the

251 model through refinements in the punching cone geometry adopted and through the displacement factors at the different sectors around the column. In the asymmetric model the inclination of the punching cone at the critical sides was $\theta=45^{\circ}$ whereas for the opposite and 
adjacent sides a flatter angle was adopted $\theta=33^{\circ}$ consisting of a first segment at $45^{\circ}$ to the horizontal until a height of $2 d / 3$ and $25^{\circ}$ to the horizontal until the centroid of the hogging reinforcement (Ulaeto and Sagaseta, 2021). For adding the shear contribution from each sector the following displacement factors were adopted at the opposite column between the critical, opposite and adjacent sides: $w_{o p p, 3.5 d} / w_{c r i t, 3.5 d}=0.65$ and $w_{a d j, 3.5 d} / w_{c r i t, 3.5 d}=0.75$ as shown in Ulaeto and Sagaseta (2021) for the geometry considered. For the post-punching calculation in the adjacent column in deformation mode 3, only one displacement factor was required, i.e. deflection ratio between the critical and opposite sides $w_{o p p, 3.5 d} / w_{c r i t, 3.5 d}=0.65$ (in this case the critical side was between the adjacent and opposite column and the opposite side was between the adjacent and back column).

The total vertical deflection at the control point $w_{c r i t, 3.5 d}$ has a component due to flexure and a component due to post-punching. The flexural component is equal to $\left(w_{c t r .1-2} / \varsigma\right)$ from deformation mode 1 where $w_{c t r .1-2}$ is the deflection at the removed column when punching of

267 the opposite column occurs and $\varsigma$ is given in Eq. (4). The post-punching component is the increment of the vertical deflection at the removed column with respect to the deflection when punching occurs $\left(w_{c t r .2}-w_{c t r .1-2}\right)$. The vertical deflection due to post-punching at $3.5 d$ from the column face was similar to that at the point where the reinforcement crossed the punching cone after local damage ( $\left.w_{p p, c r i t .2}\right)$ shown in Fig. (5) due to the small angles $\theta_{c t r, 2}$ and $\theta_{o p p, 2}$. Therefore, the displacement $\left(w_{c t r .2}-w_{c t r .1-2}\right)$ was directly taken in the post-punching model to estimate the residual shear transferred through the connection.

\section{Static and dynamic load considerations}

The removal of an internal column results in a static load redistribution; for slabs with equal spans it is generally assumed in deformation mode 1 that the load carried by the removed column is redistributed equally to the opposite columns (Regan 1981) as shown in Fig. (6). 
278 This results in a ratio of the reactions between the adjacent and opposite columns of 0.8 and 279 neglects any variation in the reactions in the back columns. These simplifying assumptions 280 neglect slab continuity and eccentricity in the loading. These static considerations were adopted 281 in deformation mode 1 to calculate the reactions at the adjacent columns from the load at the 282 opposite column, which was estimated from flexure using Eq. (1) for a given value of $w_{c t r .1}$. 283 For deformation modes 2 and 3 the reactions at the opposite and adjacent columns were 284 obtained from flexural and post-punching considerations, as described in previous sections. 285 The reactions at the back columns were not checked in this work since further modes of 286 deflections were not considered.

287 Once the nonlinear static response was obtained, the peak dynamic response (pseudo-static 288 response) was calculated using energy balance as proposed in the Ductility-Centred approach by Izzuddin et al. (2008). Fig. (6) shows the portion of the gravity loads activated dynamically considered in deformation modes 1,2 and 3 which correspond to the area of the slab mobilised

291 after column removal, punching of opposite column and adjacent columns respectively. For 292 example, in mode 1 only $75 \%$ of the load carried by the opposite column contributed to the 293 dynamic response and this fraction was $25 \%$ for the adjacent column. These approximated values estimated from geometrical considerations provided reasonable predictions of the peak deformations compared with FE results shown in the subsequent section. Deformation modes 1, 2 and 3 were applied only to flat slab systems with integrity reinforcement where the opposite

297 connection provided some significant resistance in post-punching. Deformation modes 1 and 2982 were applied to flat slab systems without integrity reinforcement where the slab failed 299 progressively after the end of mode 2 . 

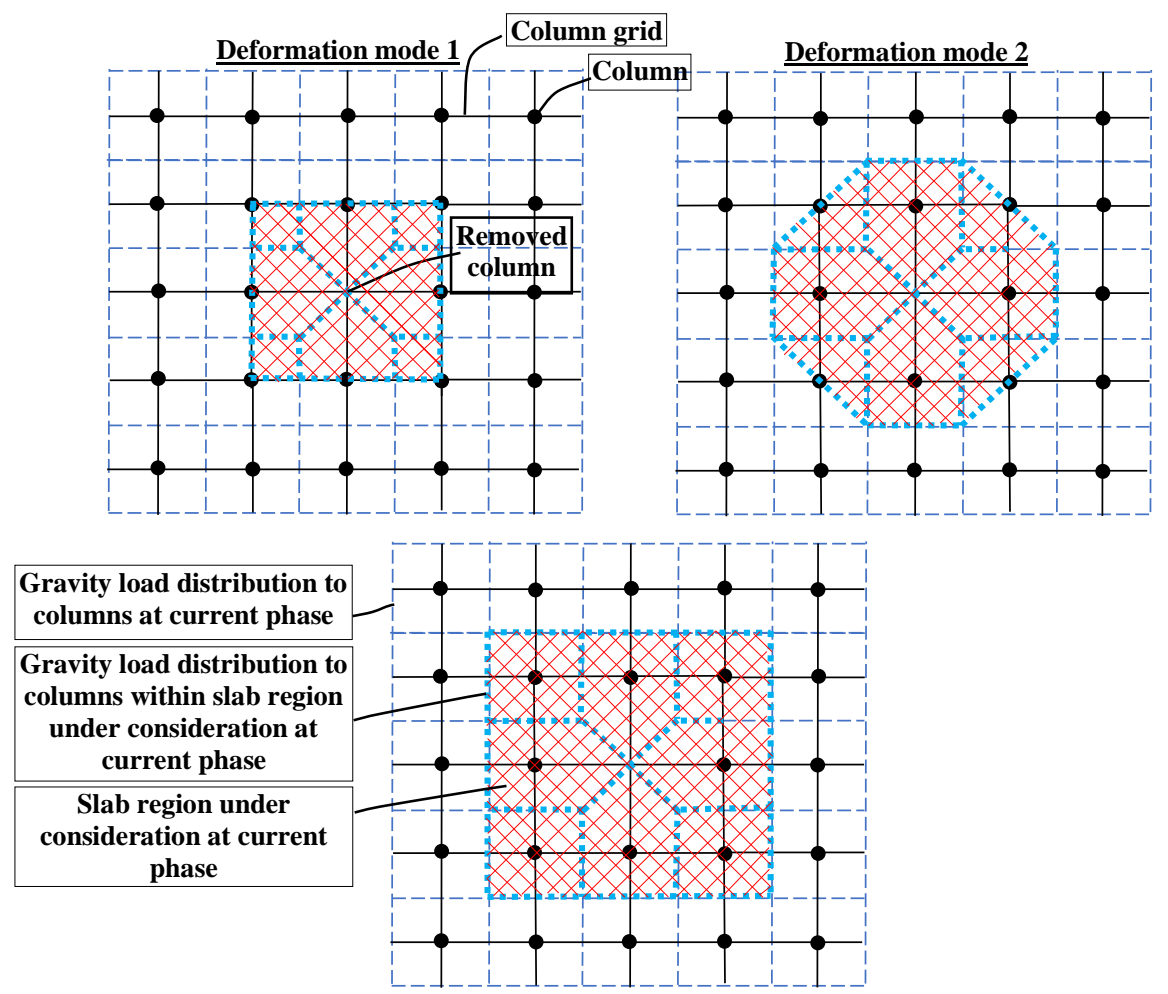

Deformation mode 3

301 Fig. 6. Gravity load distribution at three phases of response after removal of internal column.

302 The sum of the various load contributions to the dynamic response gave the total load $\left(P_{\text {stat }}\right)$

303 used in the calculation of the pseudo-static response of the flat slab system. Calculation of the

304 pseudo-static load $\left(P_{d}\right)$ for deformation modes 1, 2 and 3 was carried out using Eq. (6), Eq. (7)

305 and Eq. (8), respectively, where $w_{c t r .1 d}, w_{c t r .2 d}$ and $w_{c t r .3 d}$ are the dynamic vertical

306 displacement at the removed column in mode 1, 2 and 3 respectively. The energy balance

307 approach adopted takes into account the sudden drop of the total load $P_{\text {stat }}$ between the

308 different deformation modes resulting into a significant reduction of the slope of the pseudo-

309 static curve (large increase in dynamic peak deflection) as shown in subsequent sections. 


$$
\begin{gathered}
P_{d .1}=\frac{1}{w_{c t r .1 . d}} \int_{0}^{w_{c t r .1 . d}} P_{\text {stat. } 1} d w_{c t r .1 . d} \\
P_{d .2}=\frac{1}{w_{c t r .2 . d}}\left(\int_{0}^{w_{c t r .1-2}} P_{\text {stat. } 1} d w_{c t r .1 . d}+\int_{w_{c t r .1-2}}^{w_{c t r .2}} P_{\text {stat. } 2} d w_{c t r .2 . d}\right) \\
P_{d .3}=\frac{1}{w_{c t r .3 . d}}\left(\int_{0}^{w_{c t r .1-2}} P_{\text {stat. } 1} d w_{c t r .1 . d}+\int_{w_{c t r .1-2}}^{w_{c t r .2-3}} P_{\text {stat. } 2} d w_{c t r .2 . d}+\int_{w_{c t r .2-3}}^{w_{c t r . d}} P_{\text {stat.3 }} d w_{c t r .3 . d}\right)
\end{gathered}
$$

\section{Verification using advanced numerical models}

\section{$315 \quad$ Flat slab case study}

316 The proposed slab progressive collapse model was applied to a quarter sub-system representing

317 the internal column region of a continuous flat slab shown in Fig. (7). Edge boundary restraints

318 were modelled accordingly, including confinement restraints leading to compressive and

319 tensile action. The slab was designed according to Eurocode 2 (CEN 2004) for flexure and

320 punching for non-seismic regions. The span lengths, column size and overall slab depth were

321 adopted following guidelines in the UK (The Concrete Society, 2007); the parameters are

322 shown in Table 1. The gravity loading corresponded to a high occupancy building category

323 (C1, C2 or C3 in Eurocode 0 CEN 2010a) with a superimposed dead load of $2 \mathrm{kN} / \mathrm{m}^{2}$ and live

324 load of $3 \mathrm{kN} / \mathrm{m}^{2}$. For the design, load factors of 1.35 and 1.5 were used for the permanent and

325 live loads whereas for accidental loading (column removal) the load factor was 1 with

326 permanent, quasi-permanent and frequent factors applied to the characteristic value of the live load of $0,0.3$ and 0.5 respectively. 
H12 - 125 B2

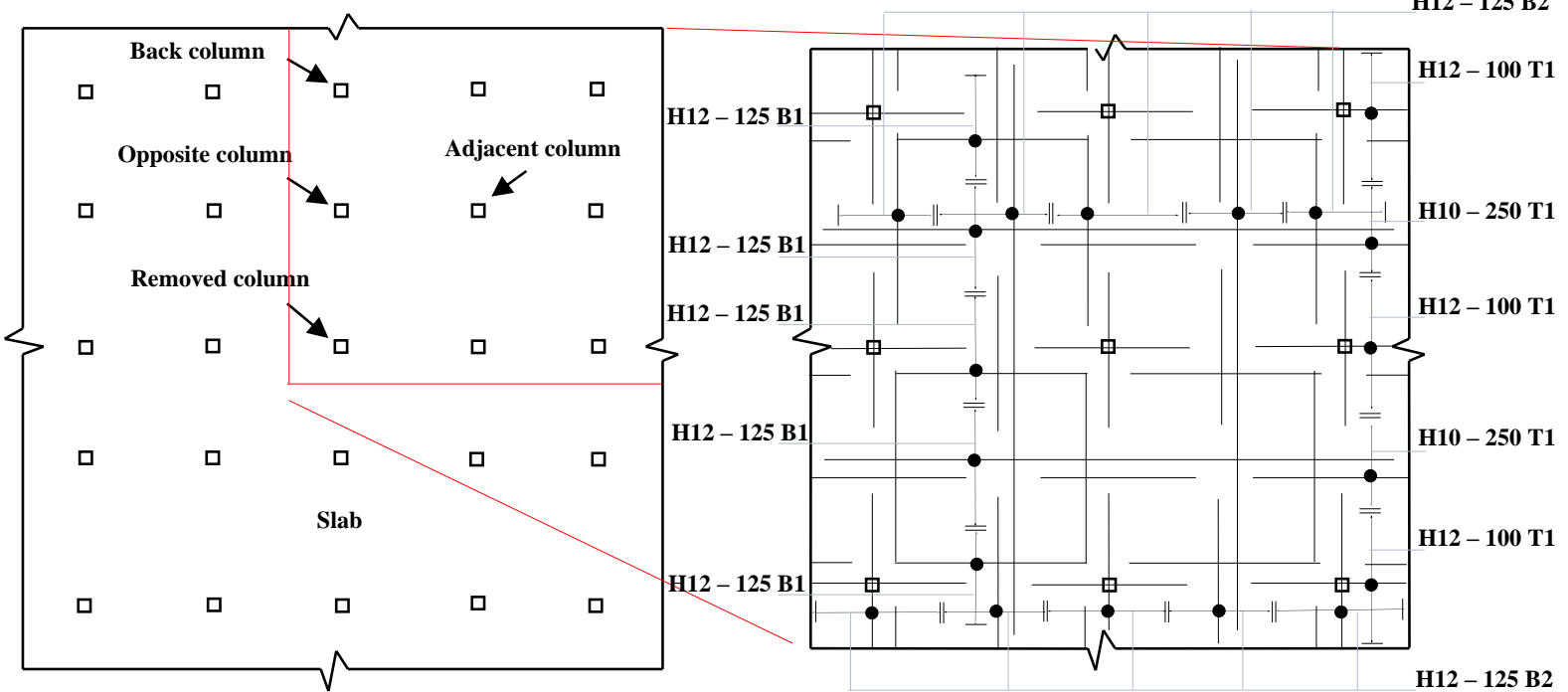

Table 1. Slab physical characteristics and material properties "B"-“T" refer to bottom-top layers and "1"-“"2" outer-inner layers).

Fig. 7. Geometry and reinforcement layout of flat slab case study (Notation key: "H" reinforcement grade B500A, B500B or B500C followed by diameter size and spacing in mm,

\begin{tabular}{lll}
\hline Characteristic & Value & Unit \\
\hline Span, $L$ & 6.8 & $\mathrm{~m}$ \\
Column strip width & 3.4 & $\mathrm{~m}$ \\
Slab overall depth, $h$ & 0.275 & $\mathrm{~m}$ \\
Nominal cover, $c_{1}$ & 0.03 & $\mathrm{~m}$ \\
Flexural reinforcement bar diameter adopted, $\phi$ & 0.012 & $\mathrm{~m}$ \\
Average effective depth, $d$ & 0.233 & $\mathrm{~m}$ \\
Concrete compressive strength, $f_{c}$ & 30 & $\mathrm{MPa}$ \\
Concrete tensile strength, $f_{c t}$ & 2.355 & $\mathrm{MPa}$ \\
Yield strength of steel reinforcement, $f_{y}$ & 500 & $\mathrm{MPa}$ \\
Ultimate strength of steel reinforcement, $f_{u}$ & 540 & $\mathrm{MPa}$ \\
\hline
\end{tabular}

333 Fig. (7) shows the flexural reinforcement layout adopted with a bottom reinforcement ratio of

$3340.44 \%$ across the entire slab and top reinforcement ratio of $0.53 \%$ at the columns. Punching shear reinforcement around internal columns was avoided in the design by providing sufficient 
336 slab thickness. The demand capacity ratio of the connections at ULS $\left(V_{E d} / V_{R d, c}\right)$ was 0.9 using

337 Eurocode 2 and Model Code 2010 (LoAII) and 0.8 using ACI 318 (2014).

338 The demand capacity ratio was consistent with FE predictions of the nonlinear static response 339 of the isolated column-slab connection in Fig. (8) using solid elements described in the next 340 section. Fig. (8) shows that the response before and after punching (i.e. deformation mode 1 341 and 2) obtained numerically was consistent with the analytical response which was based on

342 the shear-rotation curve from Model Code 2010 and post-punching model in Ulaeto and 343 Sagaseta (2021). Fig. (8) shows a case without integrity reinforcement except for two $10 \mathrm{~mm}$ 344 bars at the bottom of the slab crossing the column provided from the nominal basic 345 reinforcement mesh. The static FE and analytical post-punching models predicted that the 346 bottom bars fractured at a similar vertical deflection shown in Fig. (8). In subsequent analyses

347 of the flat slab with integrity reinforcement, two bars of $25 \mathrm{~mm}$ were provided crossing the 348 column (at both orthogonal directions); the diameter was estimated using different formulae 349 available in Mitchell and Cook (1984), ACI 352.1R-11, CSA A23.3-04 and Model Code 2010.

350 Variations of the amount of integrity reinforcement is discussed in the following sections based on the slab progressive collapse model considering also dynamic effects. 


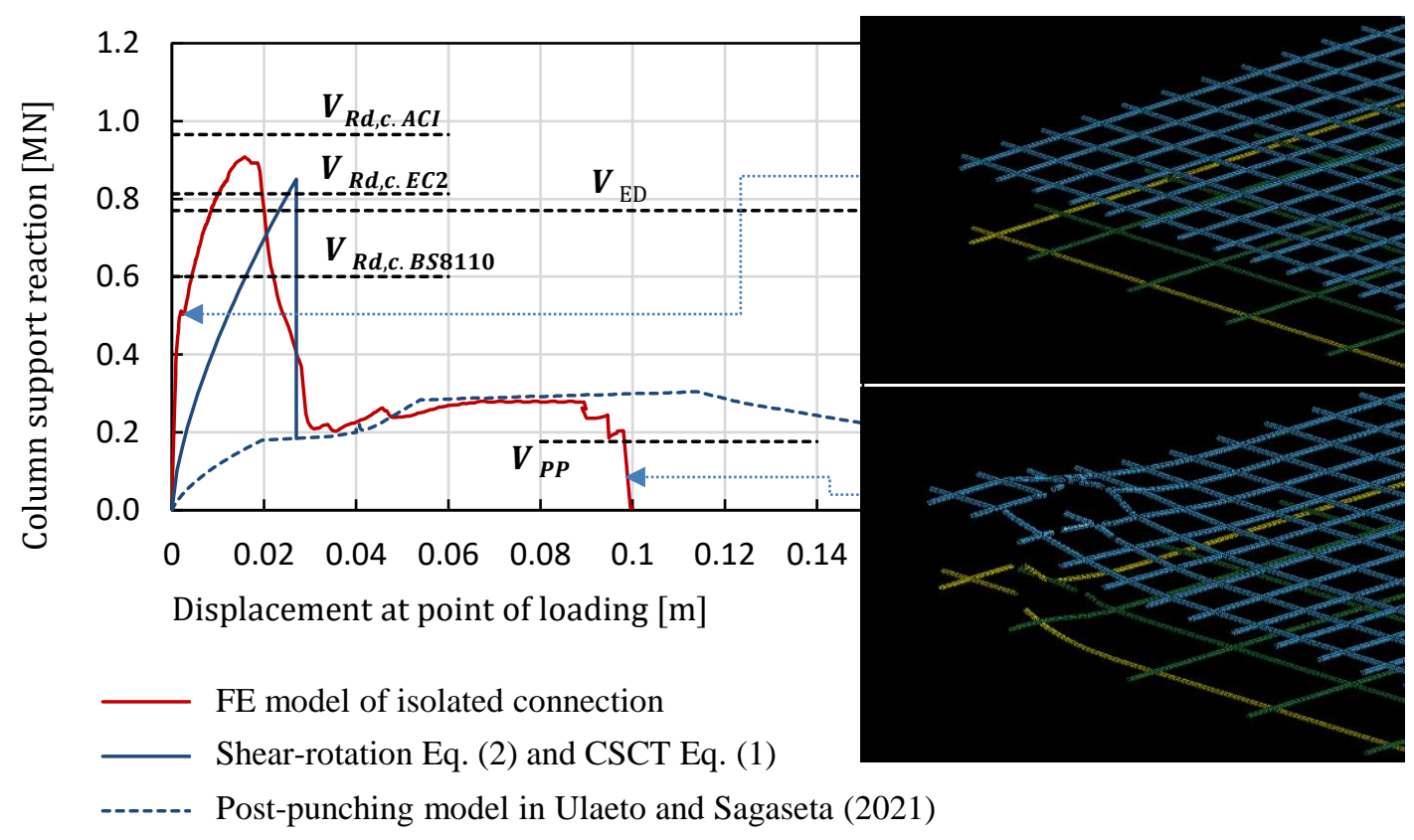

Fig. 8. Nonlinear static response of isolated column-slab connection in the case study.

\section{Numerical modelling of slab system using solid and shell elements}

The analysis of isolated column-slab connections provides limited information regarding the effects of local failure in flat slab structures since slab continuity influences significantly the horizontal propagation of failure in the slab. Modelling slab systems using shell and frame elements (e.g. Olmati et al. 2017, Liu et al. 2015) can provide useful additional information of the response up to punching of the connections which is estimated through the post-processing analysis of the shear and rotations around the column using the punching failure criteria from the CSCT (Muttoni 2008). After punching, these models need further refinement by means of connector elements (Keyvani et al. 2014, Liu et al. 2015) which can be problematic since the connector stiffness and capacity varies with the deflection and local damage of the concrete around the reinforcement during post-punching. Therefore, in this study, a 3D FE explicit modelling was adopted with solid elements for the column-slab connections, as shown in Ulaeto and Sagaseta (2021). To reduce the computational demand of the slab model, the portion of the slab outside the column region was modelled using layered shell elements whereas the slab-column region was modelled using 3D solid elements shown in Fig. (9). The solid 
369 elements were 8-noded hexagonal with Winfrith material for the concrete; embedded Hughes-

370 Liu beam elements with plastic kinematic model for the reinforcement; and Constrained

371 Lagrange solid model for the bond between beam and solid elements. For the layered shell

372 elements, the Concrete_EC2 material model was adopted (Olmati et al. 2017).

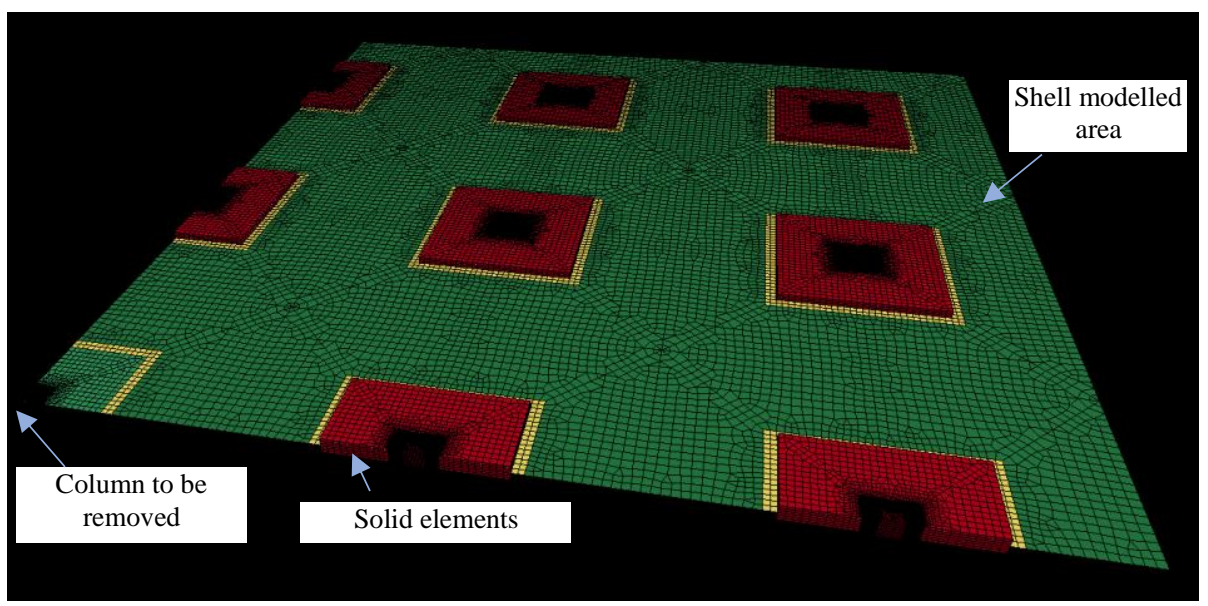

(b)
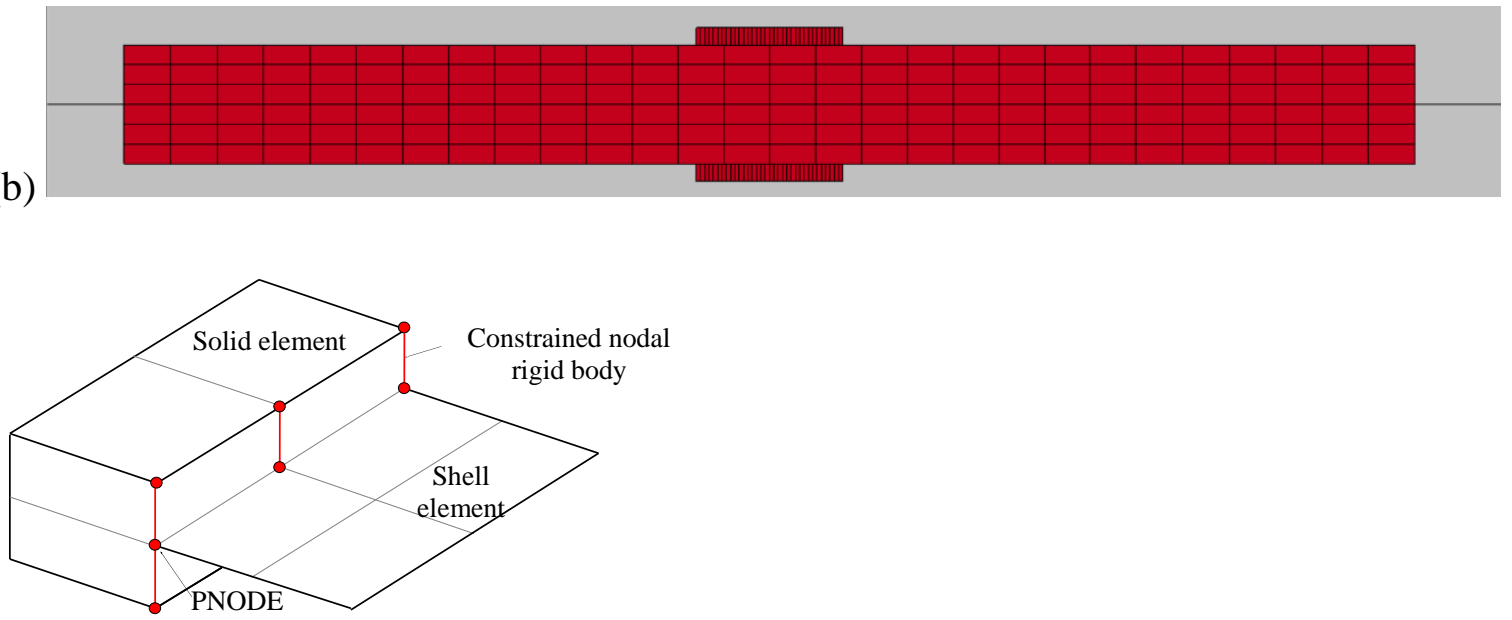

(c)

Fig. 9. (a) Quarter flat slab system model using solid and shell elements, (b) section through connection region and (c) solid-shell interface.

378 Rigid body constraints were used at the solid-shell interface to impose compatibility of rotations and displacements at the coupling plane shown in Fig. (9) for the transfer of shear and

380 bending moments. This interface was verified against isolated punching tests in the literature

381 providing similar predictions to models with only solid elements (Ulaeto 2018). In the model

382 shown in Fig. (9), the solid modelled areas extended to a distance of $6 d$ from the column face 
to capture the peak in punching and post-punching. This distance was estimated based on post-

384 punching tests (Habibi 2012 and Fernández-Ruiz et al. 2013). Columns were modelled using

$3850.1 \mathrm{~m}$ thick stubs fully restrained at the bottom as shown in Fig. (9).

\section{$386 \quad$ Nonlinear static response of slab system}

387 The nonlinear static response of the slab system described above obtained numerically was

388 consistent with the prediction from the analytical model. This is shown in Fig. (10) for the case

389 where CMA was considered, the same was true for cases where CMA was neglected. The load

390 and deflection points at which punching was predicted at the opposite and adjacent columns

391 were also predicted consistently, as well as the post-punching response. Fig. (10) shows that

392 the drop in loading after punching of adjacent connections was not as sudden in the numerical

393 response as that predicted analytically. This was due to progressive development of punching

394 and shear redistribution along the perimeter in the FE model.

395
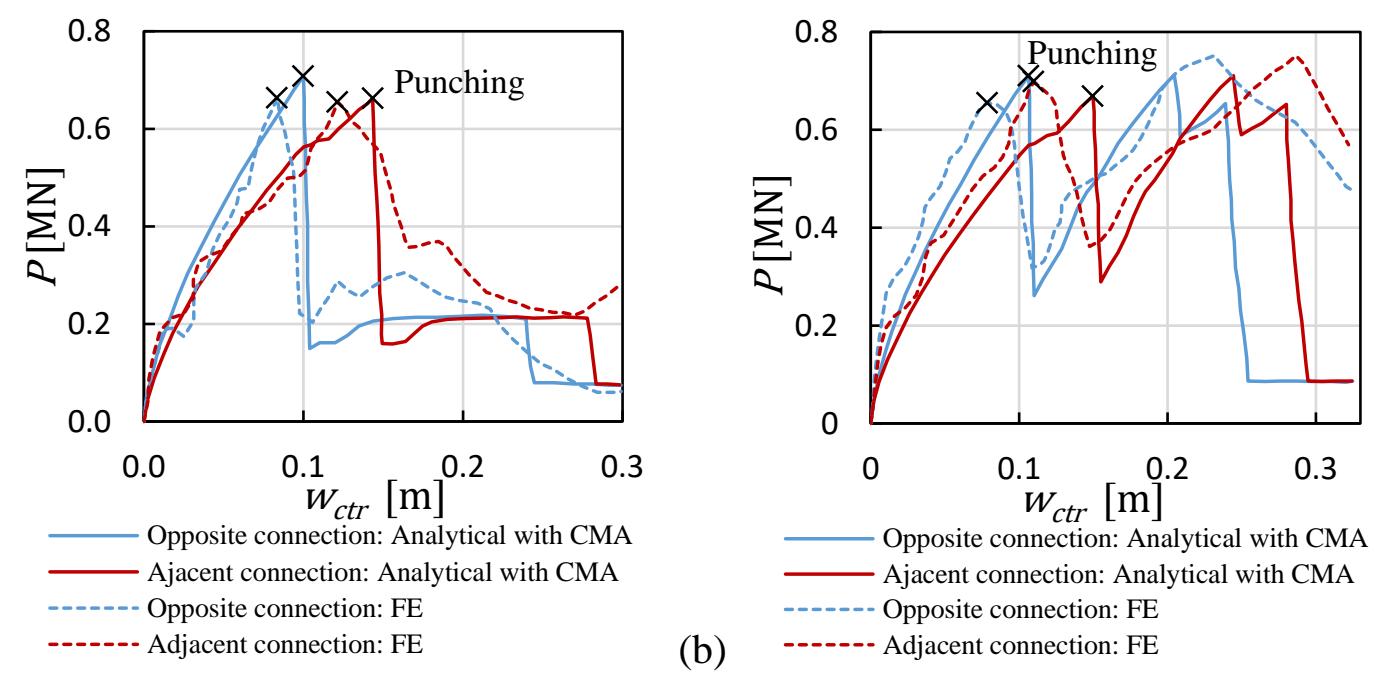

396

Fig. 10. Slab response: (a) without and (b) with integrity reinforcement.

Dynamic peak response from pseudo-static curve

398 Fig. (11) shows the pseudo-static curves obtained from energy balance (Izzuddin et al. 2008)

399 from the nonlinear static response obtained analytically in previous section. The first two peaks

400 in the nonlinear static response in Fig. (11) corresponded to punching of the opposite and 
adjacent connections; subsequent peaks were due to fracture of the flexural reinforcement and

402 the integrity reinforcement (in this order) at the critical side of the opposite column. Fig. (11)

403 shows the loads corresponding to cases of permanent $\left(g_{k}\right)$, quasi-permanent $\left(g_{k}+\Psi_{2} q_{k}\right)$,

404 frequent $\left(g_{k}+\psi_{1} q_{k}\right)$ and a load combination $1.214\left(g_{k}+q_{k}\right)$. The dynamic peak for a specific

405 load is obtained from the intersection with the pseudo-static curve.

406 The results suggest that in the case study with permanent loading, sudden column removal does

407 not result in punching of the opposite connection, i.e. only deformation mode 1 occurs and

408 horizontal propagation of failure is arrested. This result is irrespective of whether integrity

409 reinforcement is provided or not. For the case of quasi-permanent loading, punching is

410 predicted to occur at the opposite connection and not at the adjacent connection (deflection

411 mode 2 only). In this case, the provision of integrity reinforcement is critical as shown in Fig.

412 (11) since the peak (point of dynamic equilibrium) is unstable for cases without integrity

413 reinforcement leading to horizontal propagation of failure and slab falling after fracture of the

414 integrity reinforcement. As shown in Fig. (11), this can be avoided with the provision of

415 integrity reinforcement which enables the development of deformation mode 2.

416 For the frequent load combination, horizontal propagation of failure and slab falling was not

417 avoided in the case without integrity reinforcement whereas for the case with integrity 418 reinforcement the slab found a point of unstable dynamic equilibrium after punching of the 419 adjacent column. For higher load combinations, the horizontal propagation of failure and slab 420 falling was not arrested for the amount of integrity reinforcement provided; the results using 421 different amounts of integrity reinforcement are discussed in subsequent section.

422 The dynamic peak predictions described above using the pseudo-static curve were verified with 423 dynamic FE analysis using the slab system model with solid-shell elements described in 424 previous sections. The results are summarised in the next section. 

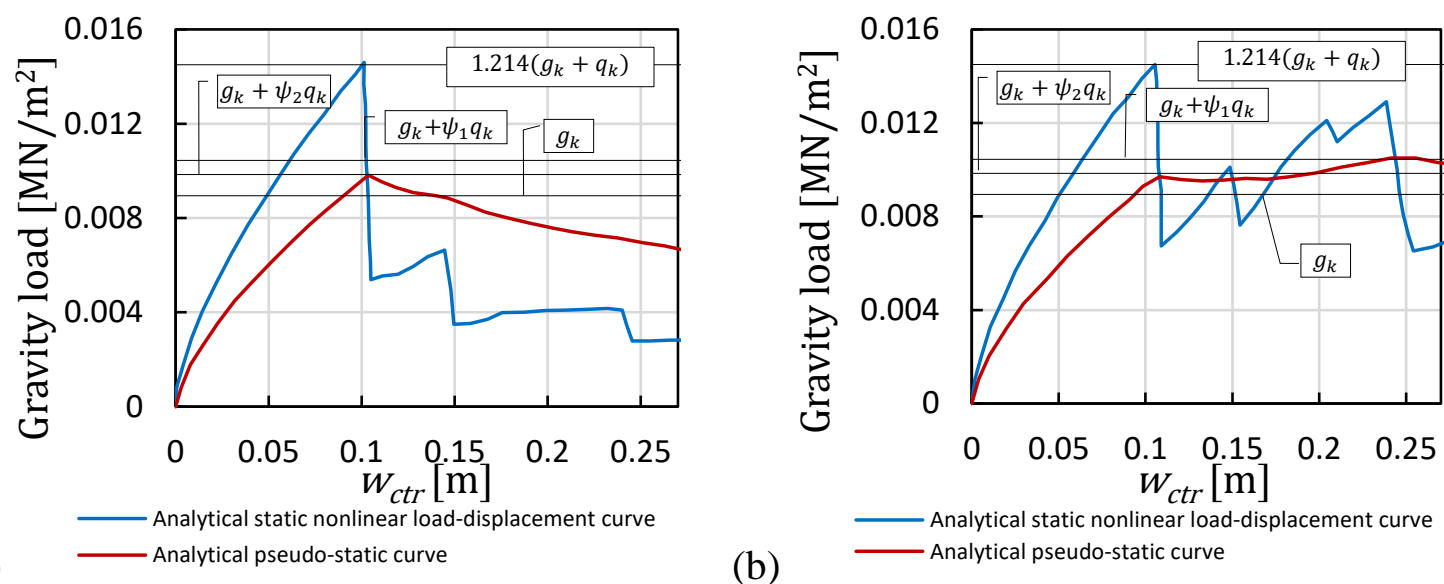

Fig. 11. System non-linear static and pseudo-static response: (a) without integrity reinforcement and (b) with integrity reinforcement.

\section{Dynamic response from nonlinear $F E$ dynamic analysis}

In order to verify the results in previous section, a nonlinear explicit dynamic FE analysis was carried out using the slab system model with solid and shell elements described previously. The gravity load was applied gradually (quasi-statically) followed by a column removal at $t=$ $6 \mathrm{~s}$ where the elements at the support were removed, resulting in a removal time of $10^{-6} \mathrm{~s}$ which is below recommended values of $T / 10$ in GSA (2013) where $T$ is the vibration period.

434 Fig. (12) shows the results for the frequent load combination with and without integrity reinforcement. In the case with integrity reinforcement progressive collapse was arrested; punching of the opposite columns was predicted at $t=11 \mathrm{~s}$ which was reflected in the sudden increase of vertical reaction in the adjacent column (Fig. (12)) which punched at around $t=$

$43813 \mathrm{~s}$. The system became stable at around $t=18 \mathrm{~s}$ with yielding of the flexural reinforcement near the opposite columns and no fracture of the integrity reinforcement. In the case without 440 integrity reinforcement (Fig. (12)), punching of the opposite column occurred at $t=8.5 \mathrm{~s}$ and

441 adjacent column punched at $t=9.5 \mathrm{~s}$ which resulted in the slab falling as shown by the sudden 442 increase in the deflection at around $10 \mathrm{~s}$. The variations in the vertical reactions in the columns 443 in the slab without integrity reinforcement followed a similar trend to the case without integrity 
444 reinforcement shown in Fig. (12) except that punching around the opposite and adjacent

445 columns occurred sooner and after punching around the adjacent column the reactions became

446 unstable and dropped to zero. The dynamic amplification factor of the shear around opposite

447 column after column removal was 1.2 which is consistent with previous studies of internal

448 column removal (Olmati et al. 2017, Liu et al. 2015, Sagaseta et al. 2017).

449 (a)

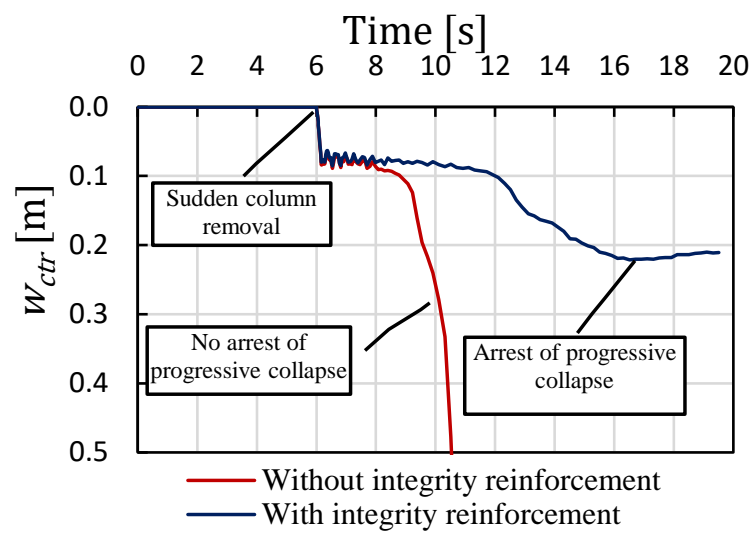

(b)
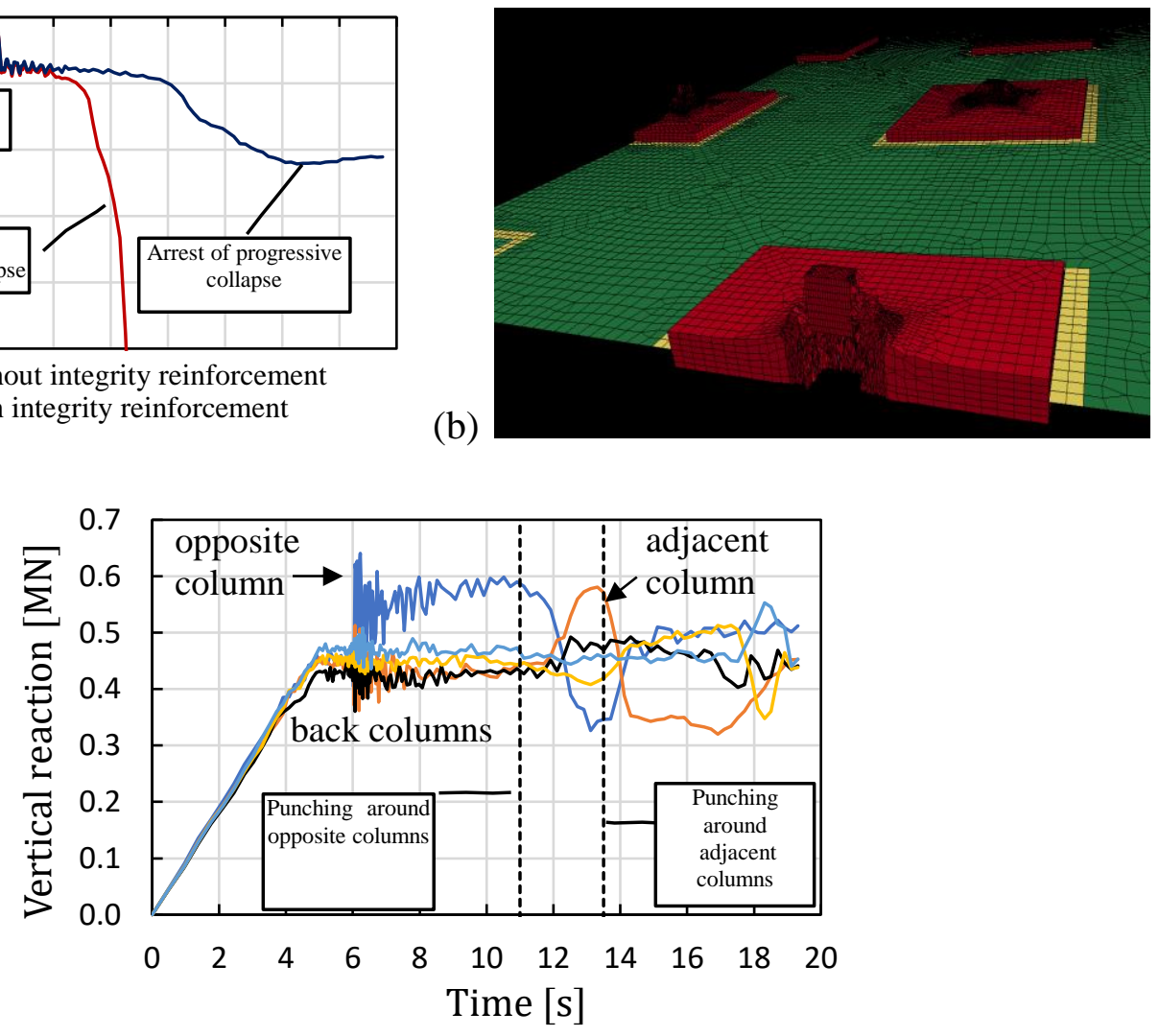

451 Fig. 12. Results from the dynamic FE (frequent load case): (a) deflection in the slab with and without integrity reinforcement, (b) damage in the connection at $\boldsymbol{t}=10 \mathrm{~s}$ without integrity reinforcement and (c) vertical reactions in the slab with integrity reinforcement.

454 Overall, the response for the frequent load case was consistent with the prediction from the pseudo-static curve in Fig. (13). The same was true for other load cases as shown in Fig. (13). In the slab without integrity reinforcement, horizontal propagation was arrested only in the permanent load case and the time at which punching first occurred varied with the gravity load 
460

(a)

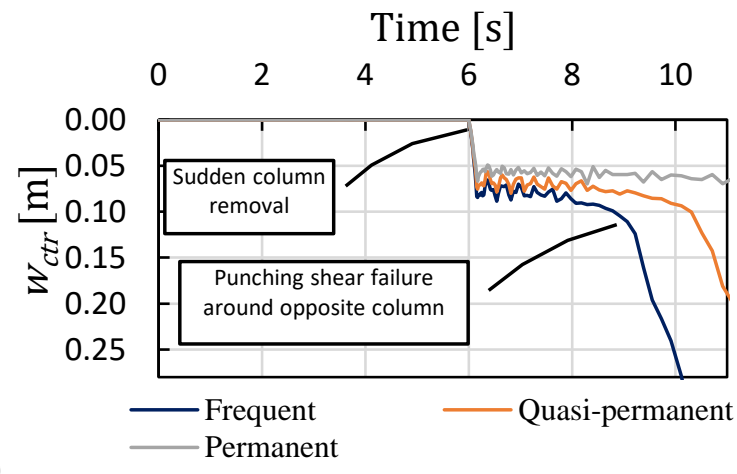

(b)

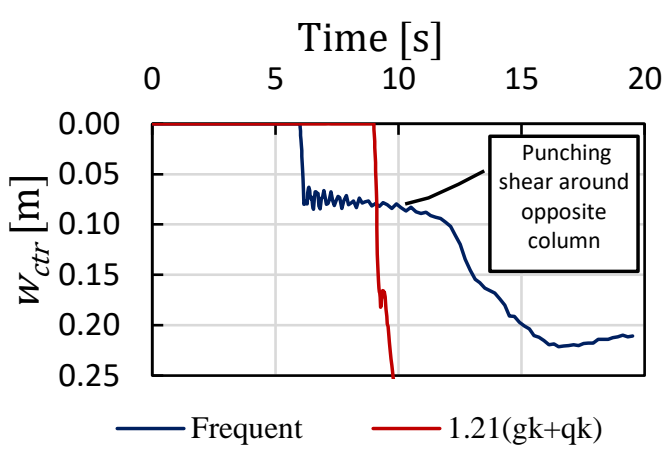

461 Fig. 13. Results from the dynamic FE for different load cases: deflections in the slab (a)

462 without integrity reinforcement and (b) with integrity reinforcement.

463 The FE model captured the development of membrane forces at the connections which was

464 consistent with the membrane behaviour adopted in the analytical model for deformation modes 1 to 3 . The member forces in the slab were determined from the FE model at the edge of the opposite column at the critical side towards the removed column with strip widths of 1

$467 \mathrm{~m}$ and $1.8 \mathrm{~m}$. The strip width of $1 \mathrm{~m}$ corresponded roughly to the diameter of the punching 468 cone estimated in the post-punching model used in the deformation mode 2 and 3 prior to local 469 damage of top concrete at the edges of the cone (Ulaeto and Sagaseta 2021). The membrane 470 force in the strip was estimated as the integral of the average normal stresses of each element 471 across the depth (solid elements for concrete and beam elements for the reinforcement).

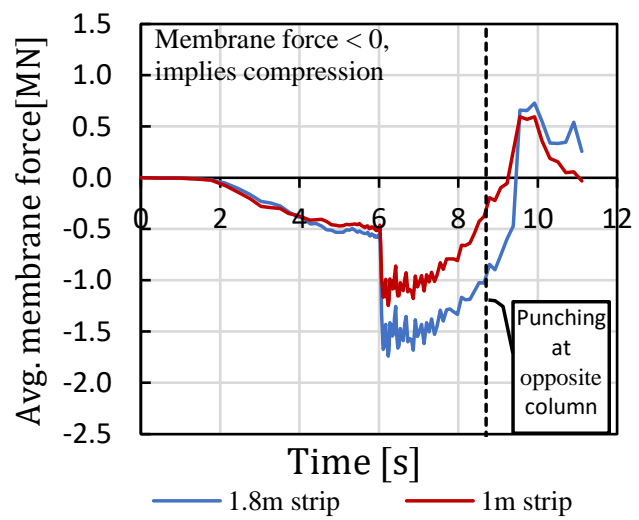

(a)

473 Fig. 14.Membrane forces (frequent load): (a) without and (b) with integrity reinforcement.

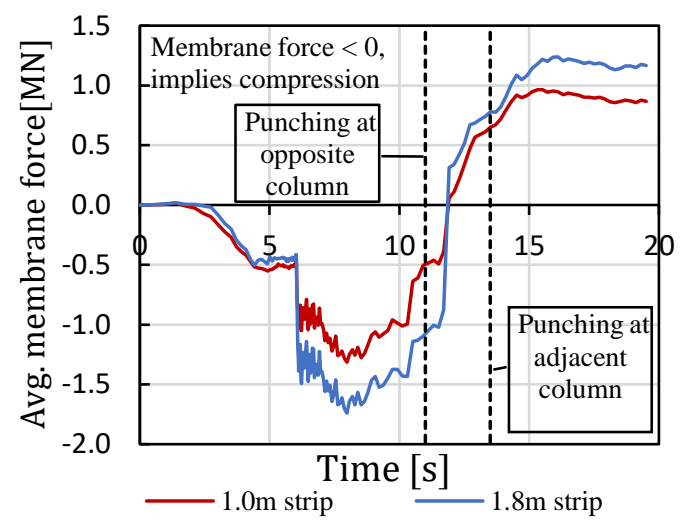

(b) 
474 Fig. (14) shows that compressive membrane action CMA increased significantly after column

475 removal; the membrane forces were around $850 \mathrm{kN} / \mathrm{m}$ which are of similar magnitude to those

476 obtained in previous studies for internal columns Olmati et al. (2017). Fig. (14) also shows that

477 the membrane forces distributed more widely across the column strip whereas tensile

478 membrane action TMA that developed at larger deflections concentrated predominantly over

479 the punching cone strip. The transition from compressive to tensile membrane action was

480 progressive from column removal until punching around the opposite column which triggered

481 the sudden change from compression to tensile membrane forces. The membrane forces were

482 close to zero when the vertical deflection $w_{c t r}$ was around $70 \%$ of the slab total depth; which

483 occurred at around $t=9 \mathrm{~s}$ and $12 \mathrm{~s}$ for the slab without and with integrity reinforcement,

484 respectively. The limit deflection obtained for CMA is reasonably consistent with theoretical

485 considerations by Rankin and Long (1997). It can be concluded that tensile membrane action

486 was activated in the slab with integrity reinforcement after large deflections. TMA concentrated

487 mainly above the column and the peak average axial tensile stress in the integrity reinforcement

488 was about $90 \%$ of the yield stress.

489 Influence of amount of integrity reinforcement and gravity load on the response

490 Sensitivity analyses were carried out using the analytical model including variations of the

491 amount integrity reinforcement within acceptable limits in current Eurocode 2 and ACI 318

492 recommendations. For the case study considered in this work, two additional cases were

493 investigated, one with two bars of $20 \mathrm{~mm}$ diameter and one with three bars of $25 \mathrm{~mm}$ diameter

494 which cover an intermediate and unusually high value case respectively.

495 Fig. (15) shows the nonlinear static and corresponding pseudo-static response for these two

496 cases. For the case of two $20 \mathrm{~mm}$ bars, the frequent load combination resulted in horizontal

497 propagation of failure and slab falling whereas for quasi-permanent loading the point of

498 dynamic equilibrium was unstable, similarly as when using two $10 \mathrm{~mm}$ bars although in this 
500 bars, for both quasi-permanent and frequent load combinations the slab resisted column

501 removal within deformation mode 3 well below the peak in the post-punching response. It is

502 interesting to note in this case that increasing the amount of integrity reinforcement was not

503 sufficient to arrest the horizontal propagation to the adjacent column.
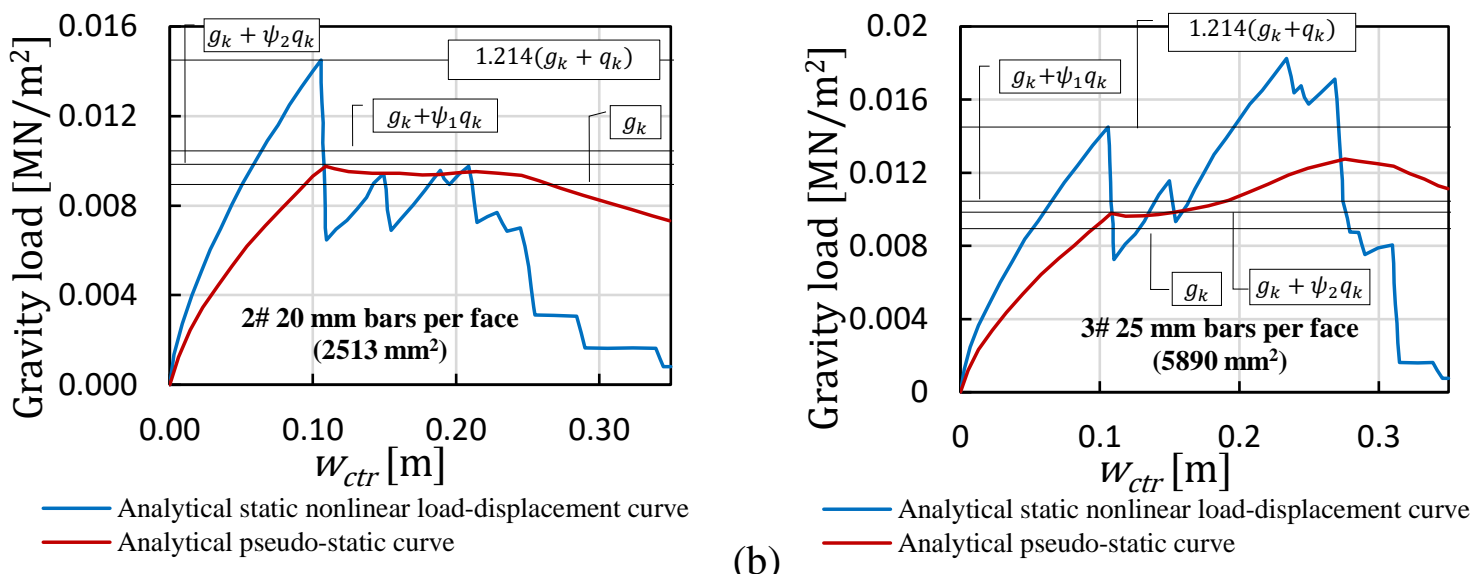

504 (a)

(b)

- Analytical pseudo-static curve

505 Fig. 15: Influence of amount of integrity reinforcement on static and pseudo-static response.

\section{Alternative notional damage scenario}

507 An alternative notional accidental scenario was considered where all the connections in the

508 slab were assumed to have punched previously. Similar to column removal, the cause leading 509 to this scenario (e.g. local or general overloading, inappropriate punching design or

510 construction) was not specified in any detail though notionally it could represent an upper

511 bound situation where punching occurs at several connections in the slab with sudden

512 propagation to other connections. Under this notional scenario, the slab system analysis is

513 simplified to that of a single connection subject to symmetric post-punching shown in Fig. (16)

514 for the two connections investigated in the case study (without and with integrity

515 reinforcement). The connection needs to resist the gravity loads in the slab when punching

516 occurs which are estimated using accidental load combination equations in design codes for

517 permanent, frequent and quasi-permanent cases. The sudden drop in the slab after punching

518 due to the significant reduction in stiffness induces a motion resulting in a dynamic 
amplification of the loads and deformations. Therefore, the pseudo-static response was

520 calculated for the post-punching curve in Fig. (16) to obtain the peak dynamic response.

521 The overall results were similar to those obtained in the column removal case, i.e. the case

522 without integrity reinforcement resulted into slab falling for all gravity loads considered

523 whereas the slab hanged from the column in the slab with integrity reinforcement. The dynamic

524 load and displacement factors obtained analytically in Fig. (16) were around 1.6 and 2.1

525 respectively; damping was neglected. The demand capacity ratio in the slab with integrity

526 reinforcement was 0.95 whereas this was 0.72 for the same gravity loading in the column

527 removal case. This suggests that the alternative notional damage scenario investigated was

528 more detrimental since the progressive propagation of failure is neglected. This alternative

529 scenario could be used in design for medium consequence class structures. However, the

530 approach does not consider explicitly the cause of the local damage and therefore more refined

531 analyses (scenario-based) are recommended for the highest consequence class structures.

532

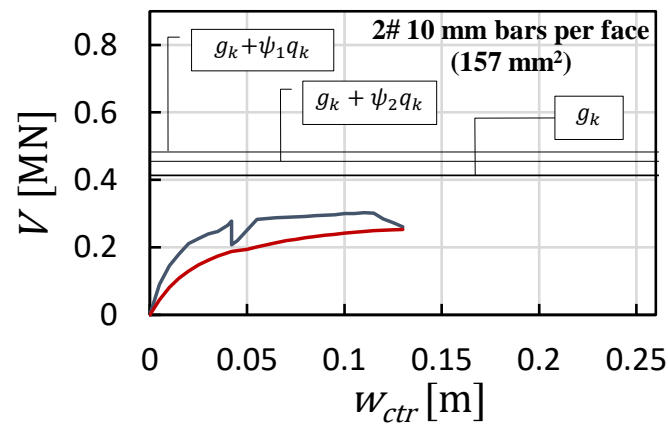

(a)

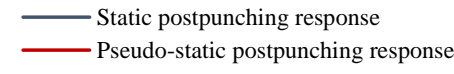

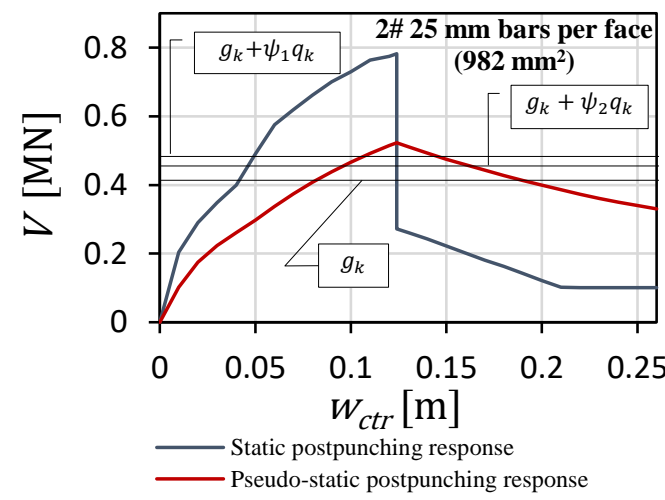

(b)

Fig. 16. Static and pseudo-static response of punched connection in notional accidental case. 


\section{Conclusions}

536 The collapse of the Word Trade Centre amongst other building failures has shown the

537 catastrophic effects of pancake-type of collapses triggered by slabs falling onto the floors

538 below. This has led to significant research on the overload introduced in the slab and

539 connections during these events. This paper shows that in flat slab construction, slab falling

540 could be prevented during the horizontal propagation of failure from the point where the

541 support is lost to other connections. An analytical slab progressive collapse model is presented

542 and applied to the critical case of slabs without punching reinforcement with different gravity

543 loadings. The analyses considered punching and post-punching behaviour at the connections

544 including dynamic and membrane effects. The analyses included cases of connections with and

545 without integrity reinforcement which is generally used in prescribed detailing for robustness.

546 The main conclusions from this work are summarised below:

547 1) In order to model accurately the horizontal progressive collapse in flat slabs, a higher

$548 \quad$ level of detail is required in the modelling of the slab-column connections compared to

549 normal design situations. The work shows that compressive membrane action and

550 flexure leading to punching are relevant at the initial mode of deformation after column

551 removal. If punching occurs at the opposite columns, refined post-punching models are

552 required which consider the local damage of the concrete near at the punching cone and

553 at slab near the column. The model should also consider the asymmetry in the

554 deflections as well as the dynamic amplification after sudden column removal.

555 2) The analyses from the proposed analytical model and numerical FE models showed

556 both cases of slab falling and slab hanging from the columns depending on the gravity

557 load considered and the amount of integrity reinforcement. The results showed that

558 integrity reinforcement was effective in preventing slab falling except when using small

559 diameter bars due to bar fracture at the critical face of the column as predicted by the 
model. The results in cases with significant amount of integrity reinforcement showed that the slab could hang from the columns although horizontal propagation of failure (i.e. punching of the adjacent columns) could not be prevented.

3) The dynamic numerical models using solid finite elements for the slab-column region provided consistent predictions of the damage and overall response to that predicted with the analytical approach. The numerical model indicated that the gradual transition from compression to tensile membrane action observed before punching had a snapexpected.

4) An alternative notional accidental scenario was investigated in which the slab was assumed to be supported on slab-column connections which had already punched. The gravity frequent and quasi-permanent loads were assumed to be activated dynamically, which resulted into a dynamic displacement and load factor of 2.1 and 1.6 respectively. The demand on the connections due to this scenario was higher than in the column removal approach which suggest that this scenario could be used in design. However, the potential application of this scenario should be investigated further since the cause of punching around the connections is not considered explicitly and therefore it might not be suitable for highest consequence class structures.

5) The work presented here shows that the phenomena and interactions between these effects (compression membrane action, punching, post-punching and tensile membrane action) is complex and therefore the study was limited to internal column removal. The principles of the proposed slab model can be extrapolated to other geometries although 
the compatibility relationships should be reviewed accordingly. The numerical model using solid finite elements is applicable to general cases although the models require a high computational demand (running each simulation took about 300 hours in a High Performance Computer).

6) Further experimental research at a building system level will be required to fully

\section{Data availability statement}

600 Some or all data, models, or code that support the findings of this study are available from the corresponding author upon reasonable request.

\section{Acknowledgments}

603 The authors would like to acknowledge the financial support of the Commonwealth 604 Scholarship Commission in the UK.

\section{References}

Adam, J. M., F. Parisi, J. Sagaseta, L. Xinzheng. 2018. "Research and practice on progressive connections in monolithic reinforced concrete structures. ACI 352.1R-11: ACI. 
ACI (American Concrete Institute). 2014. Building Code Requirements for Structural Concrete and Commentary. ACI 318-14. Farmington Hills, MI: ACI.

613 ASCE (American Society of Civil Engineers). 2010. Minimum design loads for buildings and other structures. ASCE/SEI 7. Reston, VA: CEN.

Byfield, M., W. Mudalige, C. Morison, and E. Stoddart. 2014. "A review of progressive collapse research and regulations." Proceedings of the Institution of Civil Engineers Buildings and Structures, 167(SB8), 447-456.

CEN (European Committee for Standardization). 2004. Design of Concrete Structures, part 1.1. Eurocode 2, BS EN 1992-1-1:2004, Brussels, Belgium: CEN.

CEN (European Committee for Standardization). 2010a. Basis of structural design. Eurocode 0, BS EN 1990:2002 +A1:2005, Brussels, Belgium: CEN.

CEN (European Committee for Standardization). 2010b. Actions on structures. Eurocode 1, BS EN 1991-1-1:2002, Brussels, Belgium: CEN.

CSA. (Canadian Standards Association). 2004. Design of concrete structures. CSA A23.3-04, Ontario, Canada: CSA.

Dei Poli, S., M. di Prisco, and P. Gambarova. 1993. "Cover and stirrup effects on the shear response of dowel bar embedded in concrete". ACI Structural Journal, 90(4), 441-450.

Einpaul, J., C. E. Ospina, M. Fernández-Ruiz, and A. Muttoni. 2016. "Punching Shear Capacity of Continuous Slabs." ACI Structural Journal, 113(4).

Ellingwood, B. R., and D. O. Dusenberry. 2005. "Building Design for Abnormal Loads and Progressive Collapse”. Computer-Aided Civil and Infr. Engineering, 20, 194-205.

Fernández-Ruiz, M., Y. Mirzaei, and A. Muttoni. 2013. "Post-Punching Behavior of Flat Slabs.” ACI Structural Journal, 110(5), 801-812.

fib. (International federation for structural concrete). 2013. Model Code 2010. In The international federation for structural concrete, FIB. Bulletin, Volume 2.

Garzón-Roca, J., J. Sagaseta, M. Buitrago, and J. M. Adam. 2021. "Dynamic Punching Assessment of Edge Columns after Sudden Corner Column Removal.” ACI Structural Journal, 118(2), 299-311.

GSA (General Services Administration). 2013. Alternate Path Analysis \& Design Guidelines for Progressive Collapse Resistance. General Services Administration: WA, USA.

641 Guandalini, S. 2005. "Poinconnement symmetrique des dalles en béton armé." (in French). $642 \mathrm{PhD}$ Thesis, École Polytechnique Fédéral de Lausanne, Lausanne, Switzerland. 
644 Habibi, F. 2012. "Post-Punching Shear Response of Two-Way Slabs.” PhD Thesis, McGill University, Montreal, QC, Canada.

Habibi, F., W. D. Cook, and D. Mitchell. 2014. "Predicting post-punching shear response of slab-column connections.” ACI Structural Journal, 111(1), 123-134. https://doi:10.14359.51686436

Hawkins, N. M., and D. Mitchell. 1979. "Progressive Collapse of Flat Plate Structures.” ACI J. Proceedings, 76(7), 775-808.

Izzuddin, B. A., A. G. Vlassis, A. Y. Elghazouli, and D. A. Nethercot. 2008. "Progressive collapse of multi-storey buildings due to sudden column loss — Part I: Simplified assessment framework.” Eng. Structures, 30, 1308-1318.

Keyvani, L., M. Sasani, and Y. Mirzaei. 2014. "Compressive Membrane Action in Progressive Collapse Resistance of RC Flat Plates.” Eng. Structures, 59, 554-564.

IStructE (Institution of Structural Engineers). 2010. Practical guide to structural robustness and disproportionate collapse in buildings. IStructE, London, UK: IStructE.

Liu, J., Y. Tian, and S. L. Orton. 2015. "Resistance of Flat-Plate Buildings against Progressive Collapse II: System Response.” Journal of Structural Engineering, 141(12). https://doi.org/10.1061/(ASCE)ST.1943-541X.0001295

Melo, G. S., and P. E. Regan. 1998. "Post-punching Resistance of Connections between Flat Flat slabs and Interior Columns.” Magazine of Concrete Research, 50(4), 319-327.

Mirzaei, Y. 2010. “Post-Punching Behavior of Reinforced Concrete Slabs.” PhD thesis, École Polytechnique Fédéral de Lausanne, Lausanne, Switzerland.

Mitchell, D., and W. Cook. 1984. "Preventing progressive collapse of slab structures”. Journal of Structural Engineering, 110(7), 1513-1532.

Muttoni, A. 2008. Punching Shear Strength of Reinforced Concrete Slabs. ACI Structural Journal, 105, 440-450.

Olmati, P., J. Sagaseta, D. Cormie, and A. E. K. Jones. 2017. "Simplified reliability analysis of punching in reinforced concrete flat slab buildings under accidental actions." Engineering Structures, 130, 83-98. https://doi.org/10.1016/j.engstruct.2016.09.061

Peng, Z. 2015. "Experimental and Analytical Evaluation of Disproportionate Collapse in FlatPlate Buildings". PhD Thesis, University of Missouri-Columbia.

Rankin, G. I. B., and A. E. Long. 1997. "Arching action strength enhancement in laterally- 
restrained." Proc. of the ICE - Structures and Buildings, 122, 461-467.

676 Regan, P. E. 1981. Behaviour of reinforced concrete flat slabs. Report of the Construction Industry Research and Information Association (CIRIA), Volume 81.

Russell, J. M., J. S. Owen, and I. Hajirasouliha. 2015. "Experimental investigation on the dynamic response of RC flat slabs after a sudden column loss.” Engineering Structures, 99, 28-41. https://doi.org/10.1016/j.engstruct.2015.04.040.

Russell, J. M., J. Sagaseta, D. Cormie, and A. E. K. Jones. 2019. "Historical review of prescriptive design rules for robustness after the collapse of Ronan Point.” Structures, 20, 365-373. https://doi.org/10.1016/j.istruc.2019.04.011.

Sagaseta, J., N. Ulaeto, and J. M. Russell. 2017. "Structural robustness of concrete flat slab

686

687

688

689

690

691

692

693

694

695

696

697

698

699 structures”. In fib Bulletin no. 81, ACI Special Publication ACI SP-315, 273-298.

Starossek, U., R. Smilowitz, M. Waggoner, K. J. Rubenacker, and M. Haberland. 2011 "Report of the terminology and procedures sub-committee (SC1): recommendations for design against disproportionate collapse of structures.” In: ASCE SEI 2011 structures congress, Las Vegas, USA

Tassinari, L. 2011. "Poinçonnement symétrique des dalles en béton armé avec armature de poinçonnement.” [in French] PhD Thesis, École Polytechnique Fédéral de Lausanne, Lausanne, Switzerland. https://doi.org/10.5075/epfl-thesis-5030.

The Concrete Society. 2007. Technical Report No 64- Guide to the design and construction of reinforced concrete flat slabs. Camberley, UK: Concrete Society.

Ulaeto, N. W., and J. Sagaseta. 2021. "A post-punching shear model for column-slab connections for progressive collapse analyses." Magazine of Concrete Research, 73(11), https://doi.org/10.1680/jmacr.19.00486.

Ulaeto, N. W. 2018. "Progressive Collapse Analysis of Reinforced Concrete Flat Slab Structures Considering Post-Punching and Dynamic Response.” PhD Thesis, University of Surrey, Guildford, UK.

Vlassis, A. G., B. A. Izzuddin, A. Y. Elghazouli, and D. A. Nethercot. 2009. "Progressive collapse of multi-storey buildings due to failed floor impact." Engineering Structures, 31, 1522-1534.

Wood, J. G. M. 2001. Pipers Row Car Park Wolverhampton: Quantitative Study of the Causes of the Partial Collapse on 20th March 1997. Report of the Health and Safety Executive, United Kingdom. Accessed December 08, 2020. 
707 Xue, H., B. P. Gilbert, H. Guan, X. Lu, Y. Li, F. Ma, Y. Tian. 2018. "Load Transfer and 708 Collapse Resistance of RC Flat Plates under Interior Column Removal Scenario.” J. 709 Struct. Eng. 144(7): 04018087. https://doi.org/10.1061/(ASCE)ST.1943-541X.0002090.

710 Yankelevsky, D. Z., Y. S. Karinski, and V. R. Feldgun. 2020. "Dynamic punching shear failure 711 of a RC flat slab-column connection under a collapsing slab impact.” International Journal 712 of Impact Engineering, 135, 103401.

713 Yi, W., F. Zhang, and S. K. Kunnath. 2014. "Progressive Collapse Performance of RC Flat 714 Plate Frame Structures.” Journal of Structural Engineering, 140 (9), 1-10. 


\section{Appendix A: Overview of post-punching shear model}

716 The main equations in the post-punching shear model by Ulaeto and Sagaseta (2021) are

717 summarised here for completeness. Fig. (A1) shows the definition of the main variables and

718 the shape of the punching shear cone adopted. Angles of inclination of the punching shear cone

719 to the horizontal were $25^{\circ}$ and $45^{\circ}$, for $\theta_{1}$ and $\theta_{2}$ respectively.

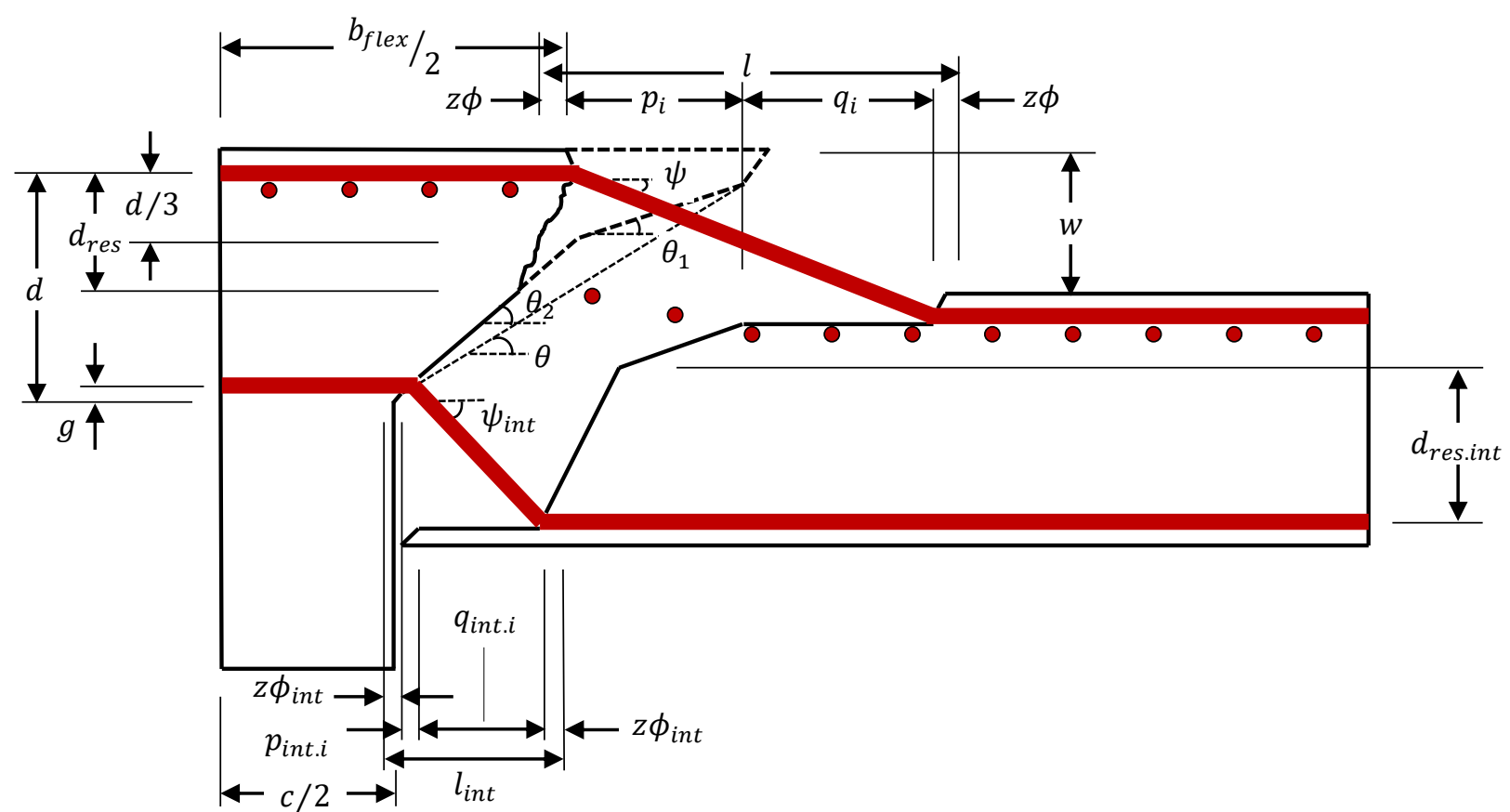

Fig. A11. Geometric assumptions in proposed analytical modelling of post-punching shear mechanism (Ulaeto and Sagaseta 2021)

722 The load-deflection response $V-w$ is obtained for the flexural reinforcement and for the integrity reinforcement separately using the approach in Fig. (A2) where the distance of local damage in the punching cone $\left(p_{i}\right)$ and in the slab $\left(q_{i}\right)$ are increased gradually to obtain the shear transferred $V$ and the vertical deflection $w$. Subsequently both curves are superimposed at points with the same vertical deflection $w$. The equations used for the modelling of the progression of the local damage and the equations used for the activation of flexural and integrity reinforcement are summarised in the following sections. 
751 As $p_{i}$ and $q_{i}$ increases, the depth of concrete above the steel bars, $d_{\text {res }}$, and the break out

752

756

760

761

762

763

764

765

$$
\begin{aligned}
& d_{\mathrm{res}}= \begin{cases}p_{\mathrm{i}} \cdot \tan \theta_{1} & : 0 \leq d_{\mathrm{res}} \leq d / 3 \\
{\left[p_{\mathrm{i}}-\frac{d}{3} \cot \theta_{1}\right] \tan \theta_{2}+\frac{d}{3}} & : d / 3 \leq d_{\mathrm{res}} \leq d\end{cases} \\
& d_{\text {res.int. }}=\left\{\begin{array}{cl}
q_{\text {int.i }} \tan \theta_{2} & : 0 \leq d_{\text {res.int }} \leq\left(\frac{2 d}{3}-g\right) \\
{\left[q_{\text {int.i }}-\left(\frac{2}{3} d-g\right) \cot \theta_{2}\right] \tan \theta_{1}+\left(\frac{2 d}{3}-g\right)} & :\left(\frac{2 d}{3}-g\right) \leq d_{\text {res.int }}<(d-g) \ldots(\text { A.6 }) \\
d-g & : d_{\text {res.int }}=(d-g)
\end{array}\right.
\end{aligned}
$$

where, $\Delta=\arccos \left(\frac{\mathrm{s}}{2 \mathrm{~d}_{\mathrm{res}} \cot \gamma}\right)$ and $\gamma=35^{\circ}$. To model the damage progression, the depth of concrete above bars $\left(d_{\text {res }}\right)$ was written in terms of $p_{i}$ or $q_{i}$.

$$
d_{\text {res }}\left(p_{\mathrm{i}}\right)=p_{\mathrm{i}} \tan \theta_{\mathrm{i}} \cot \gamma
$$

Based on geometrical considerations in Fig. (A1) and Fig. (A3). 


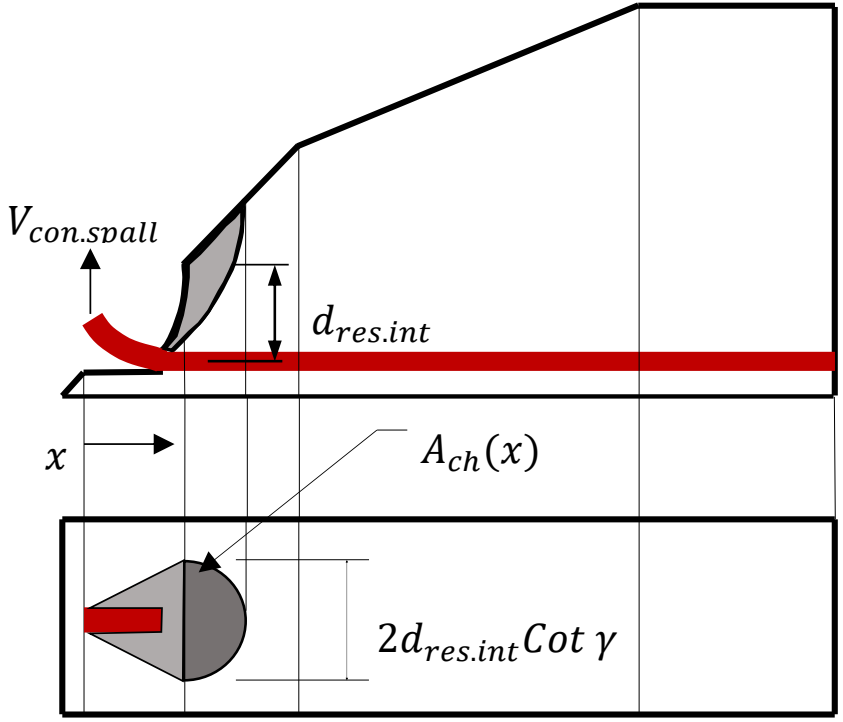

Fig. A3. Basis of analytical modelling of progression of concrete breakage

\section{Activation of flexural and integrity reinforcement}

770 The width of the punching cone, $b_{\text {flex }}$ is given by;

$$
b_{\text {flex }}=c+2 d \cot \theta-2 p_{\mathrm{i}}
$$

The total number of flexural reinforcement bars contributing to the concrete breakage of the punching cone, $n_{\text {break }}$, was calculated using Eq. (A.8). A minimum number of bars, $n_{\text {break.min }}$ was calculated using Eq. (A.9).

$$
\begin{gathered}
n_{\text {break }}=2\left[\frac{b_{\text {flex.dir.1 }}}{s_{\text {b.dir.1 }}}+\frac{b_{\text {flex.dir.2 }}}{s_{\text {b.dir. } 2}}\right] \geq n_{\text {break.min }} \\
n_{\text {break.min }}=2 c\left(\frac{1}{s_{\text {b.dir.1 }}}+\frac{1}{s_{\text {b.dir. } 2}}\right)
\end{gathered}
$$

where $s_{b}$ is the spacing of the reinforcement bars considered. The number of top reinforcement bars activated outside the punching cone by the underlying bottom layer of flexural reinforcement, is $4 q_{i} / s_{\text {b.dir.1 }}$. Hence, the total number of bars contributing to the spalling of concrete outside the punching cone is as given in Eq. (A.10).

$$
n_{\text {spa.total }}=\left[2 \frac{b_{\text {flex.dir.1 }}}{s_{\text {b.dir.1 }}}+2 \frac{b_{\text {flex.dir.2 }}}{s_{\text {b.dir.2 }}}+4 \frac{q_{\text {i }}}{s_{\text {b.dir. } 1}}\right]
$$

782 Fig. (A1) shows the length of flexural reinforcement activated around the post-punching shear transfer zone, $l$, given in Eq. (A.11) 
785

786

787

788

789

790

791

792

793

794

795

796

797

798

799

800

801 where,

$$
\varepsilon_{\mathrm{s} . \mathrm{f}-\mathrm{m}}=\frac{3 w_{\mathrm{flex}}}{l^{2}} \phi
$$
$\varepsilon_{\text {s.f-m }}$ at the tensile edge of the bar for a given displacement.

Eq. (A.14) provides the transition from flexure to membrane behaviour, given by the strain

The membrane stress in the reinforcement was calculated using Eq. (A.15) from vertical equilibrium assuming that all the shear was carried through membrane action. The inclination of the reinforcement at each step of the membrane phase is taken as the sum of the initial flexural rotation, $\psi_{\text {flex }}$, and the rotation due the strain in the membrane phase $\varepsilon_{s . m e m}$,

802 The vertical displacement of each reinforcement bar during the membrane phase, $w_{\text {mem. }}$, was calculated using the following geometric relationship

$$
w_{\mathrm{mem} .}=l \tan \psi_{\mathrm{mem}}
$$

